Historic, Archive Document

Do not assume content reflects current scientific knowledge, policies, or practices. 



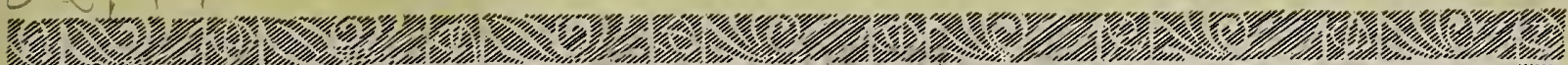

踏

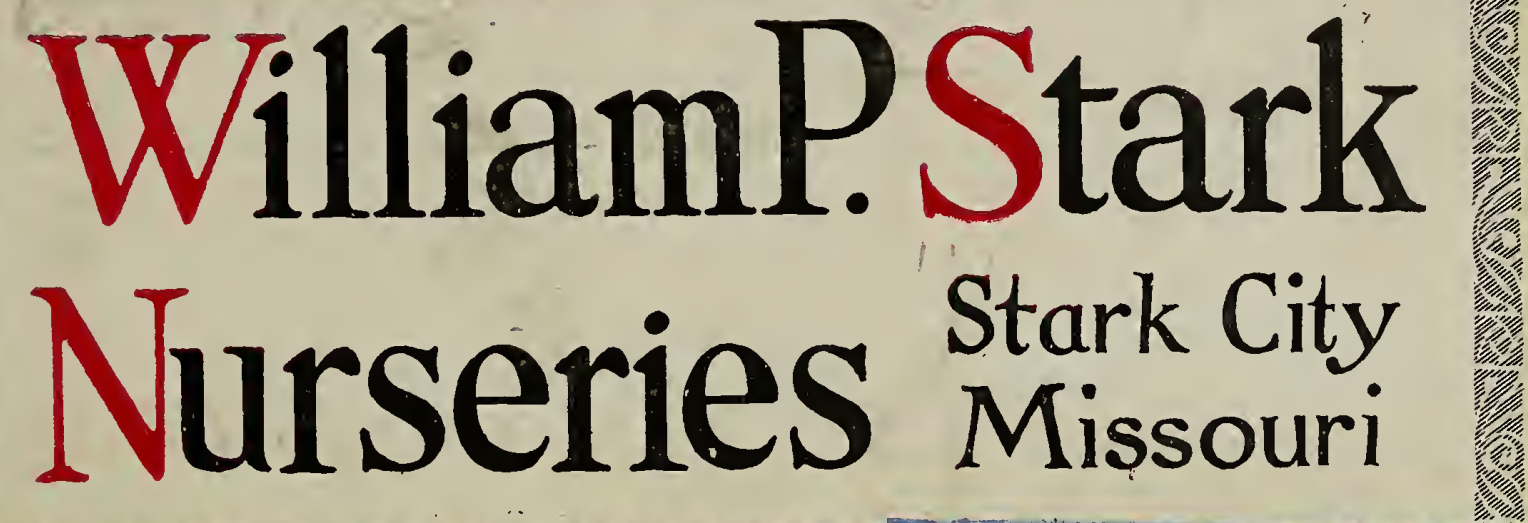

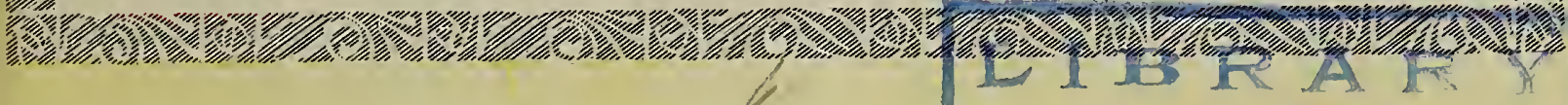

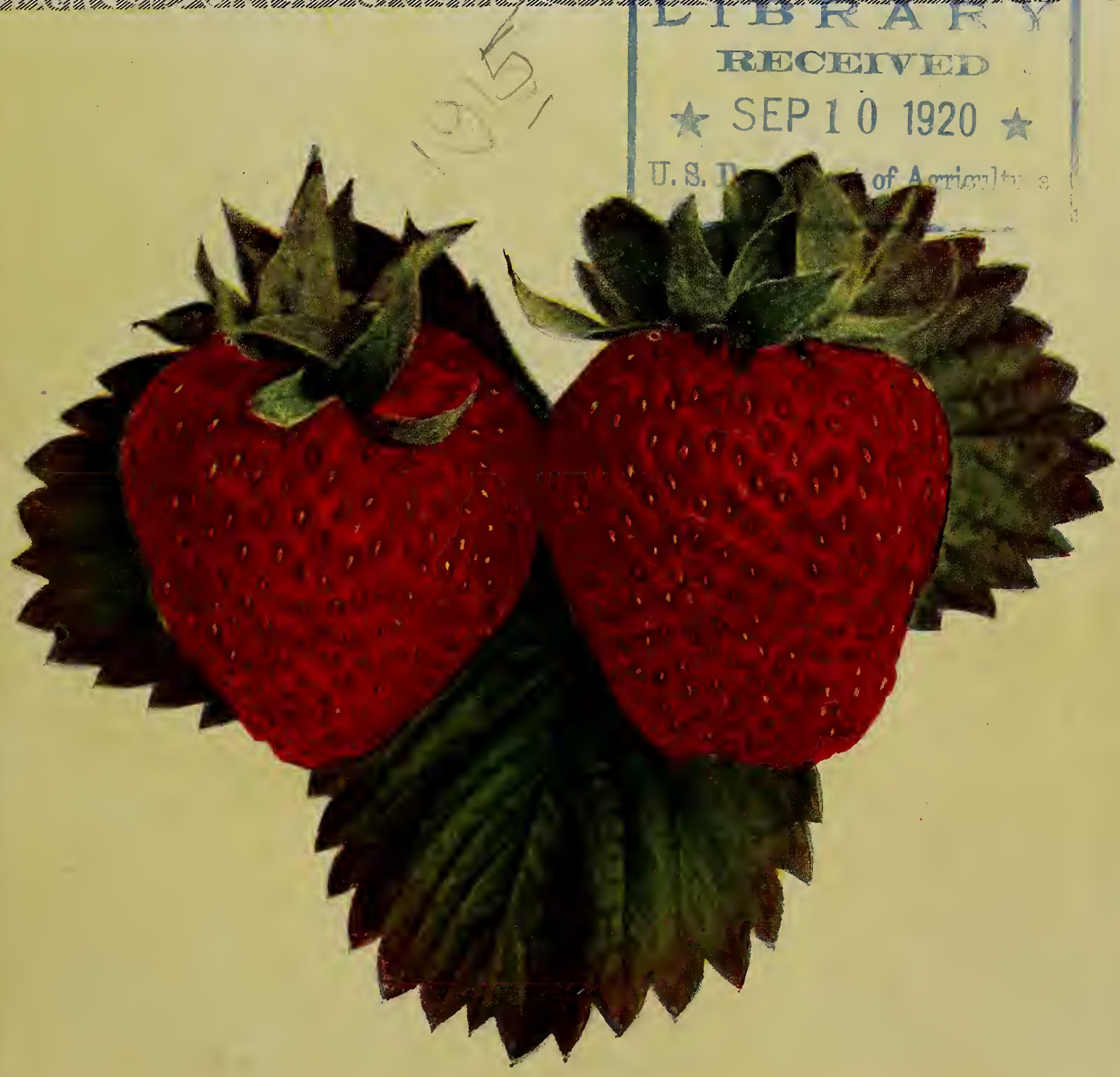
Strawberry Plants 


\section{In Orchard Rows}

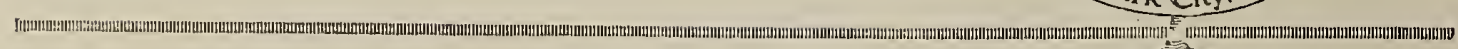
$-i$

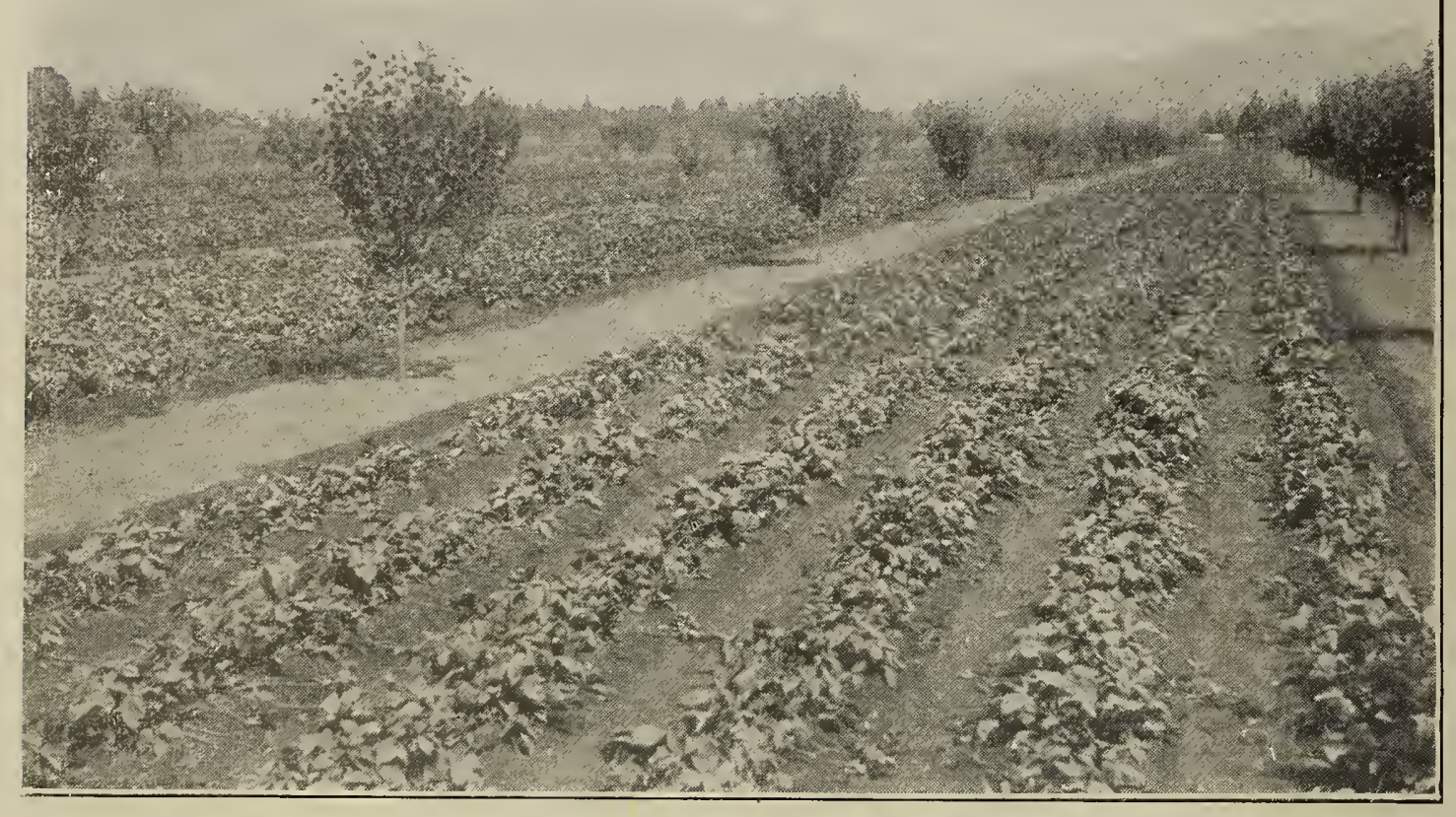

Make the land between the young trees pay dividends. Note the six rows of Strawberry plants in this young orchard.

\section{Companion or Inter-Cropping.}

A good business man makes a success because he utilizes what would otherwise be waste products and turns them into profits. As a fruit-grower, you can take profits from the otherwise waste land between the trees in your young orchard by intercropping with Strawberries, and at the same time the cultivation will help the trees.

Prof. Albert E. Wilkinson, New York State College of Agriculture at Cornell University, in his helpful book, "Modern Strawberry-Growing," says :

"The strawberry is a fine plant to use at the time of setting out a young orchard. Strawberries can be planted between the rows of trees and thereby give returns to the grower long before the trees could possibly produce any. The strawberry is considered by some people to be the very best crop for inter-planting in an orchard for the following reasons:

"1. It does not rob the trees of plant food.

"2. It does not rob the trees of sunlight.

"3. It requires good cultivation; the trees are benefited through working of the land.

"4. It requires fertilizing or manuring.

"5. Strawberries require some attention.; At the same time the grower becomes acquainted with the trees."

\section{$\$ 340$ per Acre Before the Apple Trees Came into Bearing.}

George T. Powell, well known to New York and Eastern fruit-growers, has taken four money-making crops of fruit from the same ground. He says:

"I have made $\$ 340$ an acre at Orchard Farm, Ghent, N. Y., from four crops of fruit on the same ground. The apple trees, planted forty feet apart, were not in bearing. Between them peaches were inter-planted twenty feet apart, currants five feet apart, and strawberries in between. "The currants paid $\$ 75$ to $\$ 100$ an acre, peaches $\$ 140$, and strawberries $\$ 100$." 


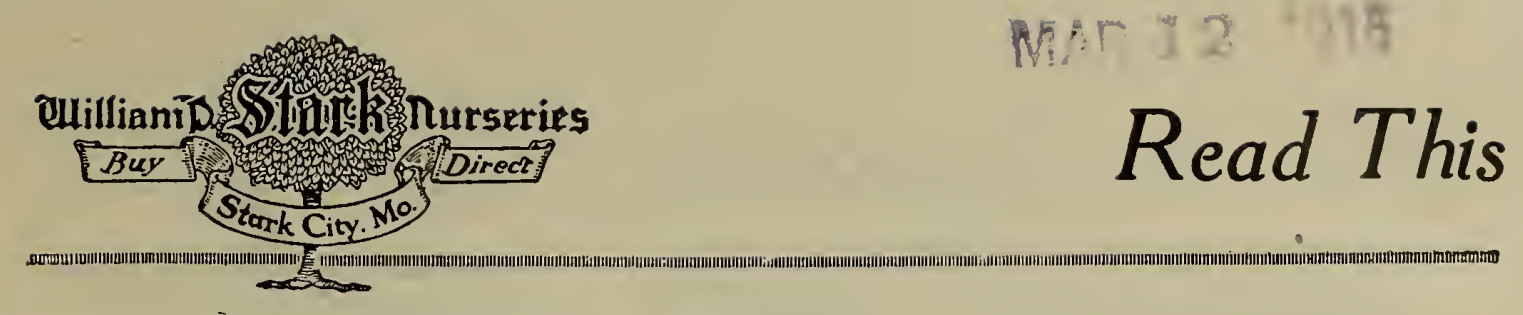

\section{Terms.}

The William P. Stark Nurseries sell Strawberry Plants'direct from ${ }^{\top}$ the Nurseries to the planter. Our desire is to do everything for you that we can do better and cheaper than you can, giving you the best service at the lowest possible cost. It is to our mutual advantage to furnish the best Strawberry Plants and Trees, deliver them promptly and in good condition, at the lowest cost consistent with the highest quality.

Each plant is doubly guaranteed true to name. Only the most experienced men-men who have worked in the Nursery all their lives-have charge of the work in the different propagating and packing departments. Every precaution is taken to have each plant true to label. If from any fault of ours plants are not true to label, we will, on proper proof, either (1) replace double the number, or (2) refund the price paid plus 6 per cent compound interest, and also replace the actual number of plants free of charge. This is a guarantee that guarantees. It means something. It is worth while, and you can depend on it.

William P. Stark Trees are guaranteed free from injurious insects and fungous diseases. All stock is doubly inspected by the State officials and by our own entomologists, who co-operate with the State officials and go over the Nursery carefully each season. Every precaution is taken to safeguard the buyer of William P. Stark Strawberry plants.

Packing and guaranty. The safe arrival of your order is assured. We take extra care in packing our plants and guarantee all express or mail shipments to reach their destination in good order. Any shipments lost or injured en route will be replaced free of charge if we are notified promptly. Boxed and packed free.

Shipping. The majority of Strawberry plants are sent by express. The lower Express rates, which have been reduced in competition with Parcel Post, are practically as low and service equally as good, except where the planter lives some distance from town, and there it is an advantage to ship the plants by Parcel Post and have them brought out by the Rural Free Delivery carrier. Strawberry plants are sometimes sent by freight and it is reasonably safe for early shipments when the plants are entirely dormant; however, we do not recommend it and all freight shipments are made at purchaser's risk. All orders delivered free on board cars Stark City.

Order early. The sooner you set the plants in the spring, the stronger and the more numerous runners they will produce, and the larger and more vigorous rows you will have for next year.

Planting time. Spring shipment is generally best. We can ship from March 1st to May 1st. However, it is sometimes possible to ship in February. We ship plants at the right season, depending on weather conditions throughout the country. Unless you give a specific shipping date, we will forward your order as soon as weather conditions are favorable for planting.

We can also deliver plants in the fall where that is required. Fall-set plants should be planted at least two weeks before there is danger of a hard frost.

We grow the plants we sell and have no agents, but deal direct with you. All of our business is done under the name of the William P. Stark Nurseries, Stark City, Missouri. Our price is the lowest possible, based on selling direct from the Nurseries and cutting out all agents and traveling salesmen's expense.

Club orders. Go in with your neighbors and all buy together, thus saving money. Get the benefit of the special discounts on large quantity orders by combining your order with that of your neighbors.

Special prices to large fruit-growers and co-operative associations quoted on request. Prices printed in this catalog are net cash with order and apply on any quantity to 3,000 plants. On larger quantities we will allow discount as follows:

3,000 to 5,000 plants, $5 \%$ discount; 10,000 to 25,000 plants, $15 \%$ discount.

5,000 to 10,000 plants, $10 \%$ discount; 25,000 to 50,000 plants, $20 \%$ discount.

TERMS: Cash with order, or half cash, balance any time before shipment. No plants sent C. O. D. 


\section{Stark City Strawberries}

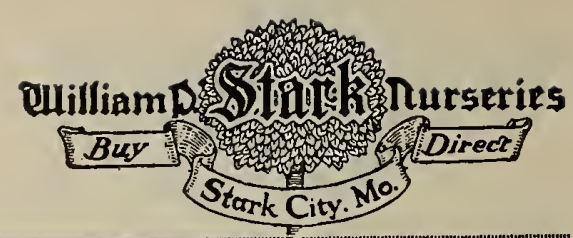

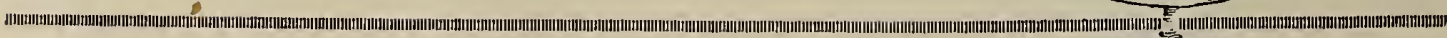

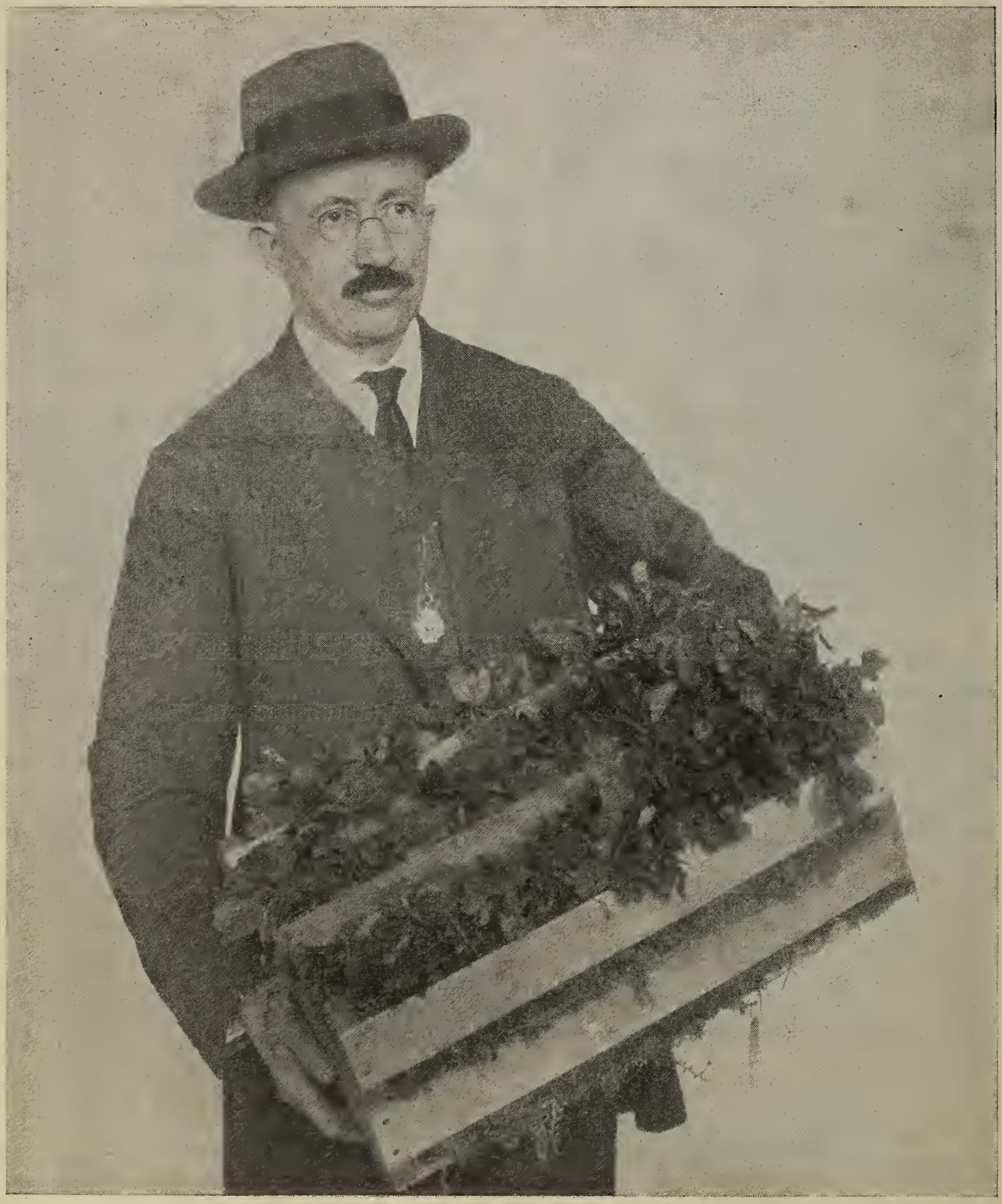

\section{William P. Stark Ozark-Grown Strawberry Plants.}

At Stark City, Missouri, we specialize on growing Strawberry plants just as we specialize on the growing of fruit trees. The men in charge of our Strawberry-propagation are all experts, working under the direct supervision of William P. Stark. They give all their time to growing and delivering your plants to you in perfect condition. Professional Straw. berry-growers use William P. Stark's scientifically grown plants because they have the same vigor and dependability that have made William P. Stark trees famous among orchardists everywhere.

The crate which Mr. Stark is holding shows how we make express shipments. Strawberry plants must be packed so as to admit a circulation of air. Trees, on the other hand, are dormant, and are packed in air-tight packages. 


\section{Strawberry Plant Specialists.}

Experienced berry-growers demand the best grade of Strawberry plants at. a reasonable price. To meet this demand we have concentrated our efforts in propagating selected plants and keeping down the cost of production by specialized tools and methods. At Stark City we have another advantage in our warn, mellow, upland, Ozark soil, which experts say is unsurpassed for Strawberry culture. The hundreds of carloads of Strawberries that are shipped out of this section every season prove it. In the days before Strawberry-growing became a commercial industry, it was a common practice to take plants from old fruiting beds. The commercial plant men were, as a rule, berry-growers, who sold plants out of their fruiting beds. The plant nurseryman grew the berries for the fruit, and sold the plants from his beds as a side line. He was not in the plant business, but in the fruit business, and plants were a by-product of secondary consideration.

\section{Scientifically Grown Plants Versus Those From Old Fruiting Beds.}

The practice of using plants from old fruiting beds is bad. It is like using seed-corn or seed-wheat from the same field over and over again, and is strongly condemned by leading Strawberry experts everywhere. Inexperienced growers do not realize their loss from using cheap, inferior plants, which are dear at any price. It takes more of these so-called cheap plants to establish a bed, so that they really cost more in the end, and the results are not as satisfactory. If you will examine a Strawberry plant, you will see the reasons why this is true. The Strawberry is a perennial. It has a fleshy central "crown" just at the surface of the ground, with the roots extending from the lower end of the crown and the leaves from the upper end. The plants are multiplied by runners which grow from the top of the crown with the leaf stems. These runners extend out some inches and then the end puts out leaves and roots. Thus a new plant is developed.

\section{VIGOROUS}

MOTHER-PLANTS
This new plant is connected by the runner to the mother-plant, which continues to nourish it for some time. Strcng, vigorous runners can be produced only by healthy young mother-plants, which have not been weakened by fruiting. As the new runner-plant grows, it in turn puts out a runner, each continuing to multiply. From one strong, vigorous mother-plant, twenty to forty and sometimes fifty or more new plants are formed in one season. The number of new plants formed depends on the vigor of the first mother-plant.

PLANTS FROM All of the vigor from fruiting plants is given to proNEW BEDS

ARE BEST ducing the crop of berries and they are not able to give the strength that is necessary for producing the required number of healthy, lusty, young runner-plants. The reresult is, that if you set your new Strawberry-field from runners taken from 


\section{Stark Ctty Strawberries}

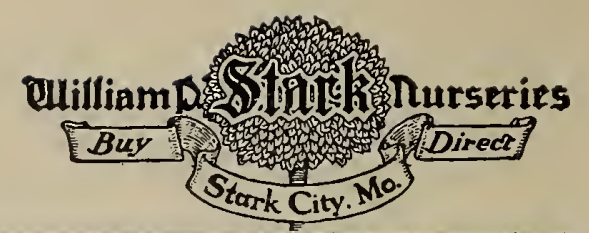

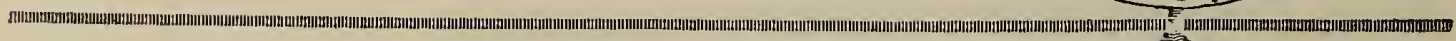

(1)

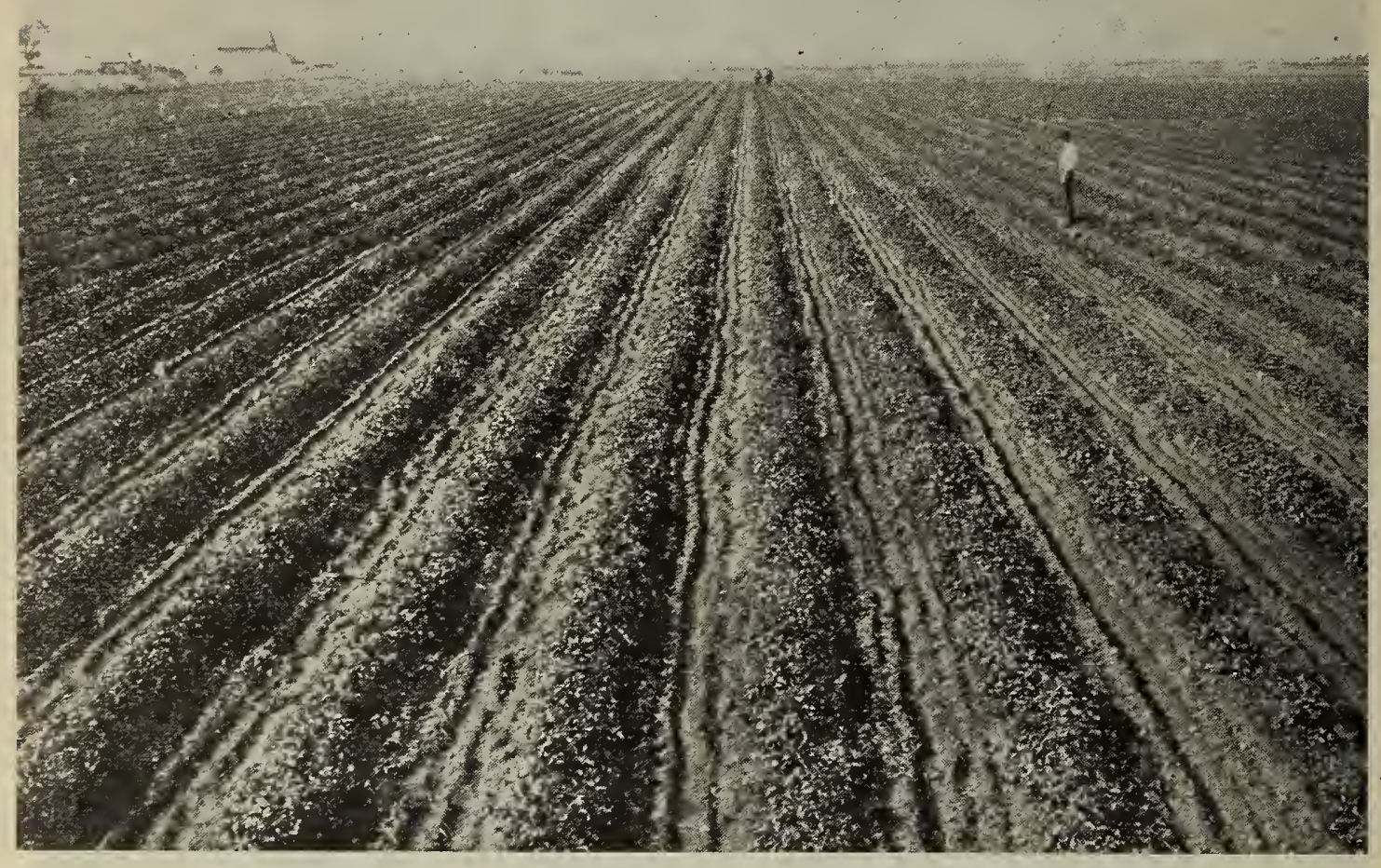

One of the Strawberry plant beds at Stark City. Over 7,000,000 plants.

an old fruiting bed, you may not get as many plants as are needed to form a good fruiting row, and the crop will be light. The difference between this light crop on plants from old beds and the full crop you would have gotten on plants from new beds would pay the entire cost for planting your field several times over. Further, because your new plants from old beds are not strong and vigorous, they will not produce berries of as good quality, and these will not bring the top prices.

There is another risk run in taking plants from old fruiting fields. These old beds become infected with insects and disease. They can not be kept entirely free from such pests, and even though they may not be serious in the old field, they will infect your new Strawberry fields from the first and may cause serious trouble before the beds are well started.

WM. P. STARK

We grow all of our Strawberry plants which we sell at METHODS

Stark City, Missouri. These plants are taken from the propagating-beds and shipped immediately to you. We propagate from select strains of the best varieties. Our plants are set out very early in the season, and the cultivation starts the day they are planted. When the bloom clusters appear, they are pinched off immediately to prevent fruiting. This forces the early development of runners. In the fruitbearing Strawberry field, runners are formed, but they do not develop to any extent until after the crop is matured and picked. By the time the ordinary fruiting berry-field is bearing its crop in the spring and early summer, William P. Stark plants have developed a very large number 


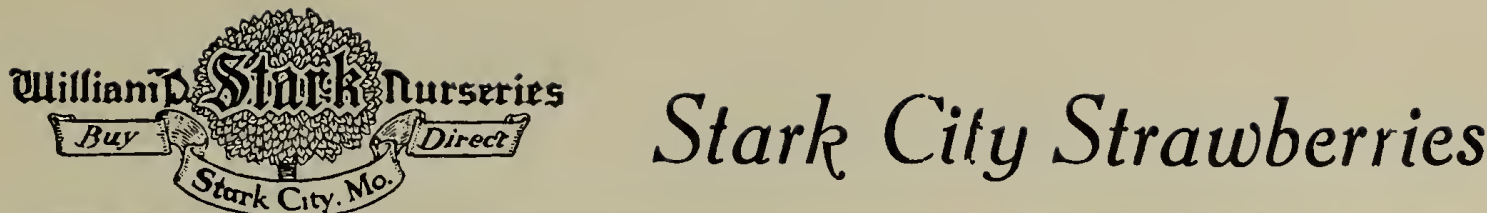

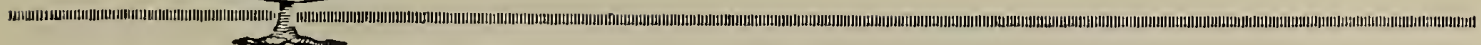

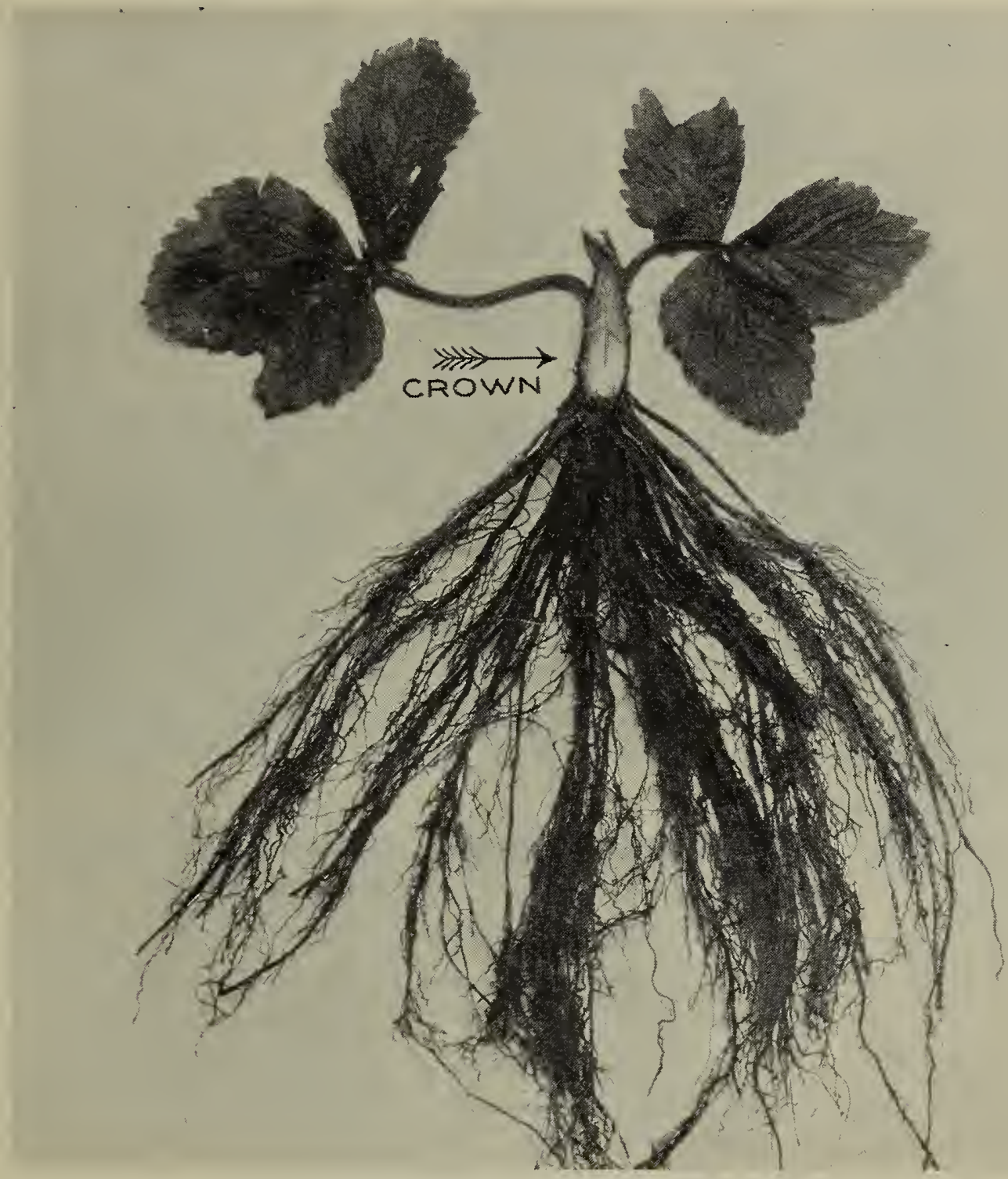

Crown of William P. Stark Strawberry plant cut in two to show size and large quantities of stored-up plant food.

of runners in our propagating-beds. They have a longer time in which to mature and increase in size than is pessible for the runners in fruiting fields. All the strength of the William P. Stark plants is given to developing large, heavy, sound crowns with strong, vigorous roots and clean, healthy foliage.

NEW BEDS EVERY YEAR

We take up the propagating-beds each season, never letting them "stand over" from one year to another. In this way each plant gets the full benefit of new fresh land and of constant clean cultivation that is not possible under any other system. The photograph on page 4 shows our method of cultivation, not a weed among seven million plants. This is specialized propagation. The result is plants of vigor and quality not dreamed of by old-time Strawberry plantgrowers. 


\section{Stark City Strawberries}

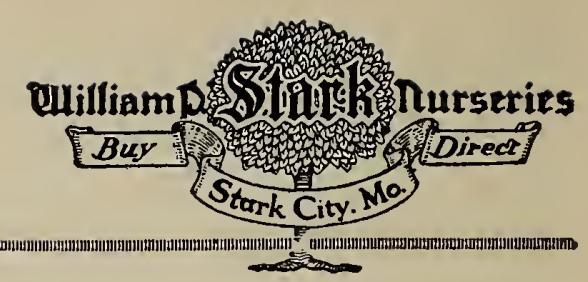

\section{HEAVY CROWNS}

\section{MEAN STRONG PLANTS}

Stark City is in the heart of the Ozark Mountain Strawberry country. Hundreds of carloads of luscious ripe berries are shipped from this lo-

cality every year. Our Stark City soil is an upland type, very mellow and fertile, with a gritty quality that produces large, lusty plants with heavy crowns and roots. The crown is the very heart of the Strawberry plant. Notice the photograph on page 5 showing this crown split in two. It is a clear white solid meaty substance, stored full of plant food. The strength and number of the new roots and leaves depend upon the size and condition of the crown and the amount of plant food stored there. A William P. Stark Strawberry plant, strong and vigorous, properly set out early in the season, will put out vigorous runners, which will produce large quantities of fruit the following season; further, these plants that are formed will in turn put out other runners, and these will be strong, vigorous, and continue to multiply. In the North, especially where the growing season is comparatively short, it is highly important that you set the strongest, best-rooted plants that are possible to secure. The time is limited, and the plants which you set should start making runners promptly so as to develop a thick, heavy fruiting row for the coming season's crop.

PACKING AND It is just as important to have your plants handled and SHIPMENT cared for properly as it is to get good plants.

When digging the plants in the William $\mathrm{P}$. Stark Nurseries, we take up. the entire row, and do not carry our propagatingbeds over, but furnish plants from fresh beds of one season's growth. The plants are taken immediately to the Packing House without exposure to the air and sun. In the Packing House the dirt is removed from the roots and the larger leaves are clipped off, which prevents injury from evaporation. (In transplanting the larger leaves should always be removed.) The plants are then tied in bundles of twenty-five. This cleaning helps the plant. It costs money, but it makes it possible for us to deliver the plants to you in perfect condition.

The plants are then packed in crates or split baskets with slatted tops, with Sphagnum moss about the roots. We get this moss from Northern Wisconsin or Michigan. It never heats and it holds just enough moisture to insure the plants reaching you in perfect condition without making them wet or soggy, and it practically eliminates all danger from either heating or drying out.

\section{IMPORTANCE OF} CAREFUL PACKING
The tops of the plants are packed close together, but in a way to allow a free circulation of air.

The Strawberry plant stops growing in the fall and goes into a resting condition, but it never becomes entirely dormant like hard-wooded trees and shrubs. The Strawberry plant-tissues are succulent, 


\section{Stark City Strawberries}

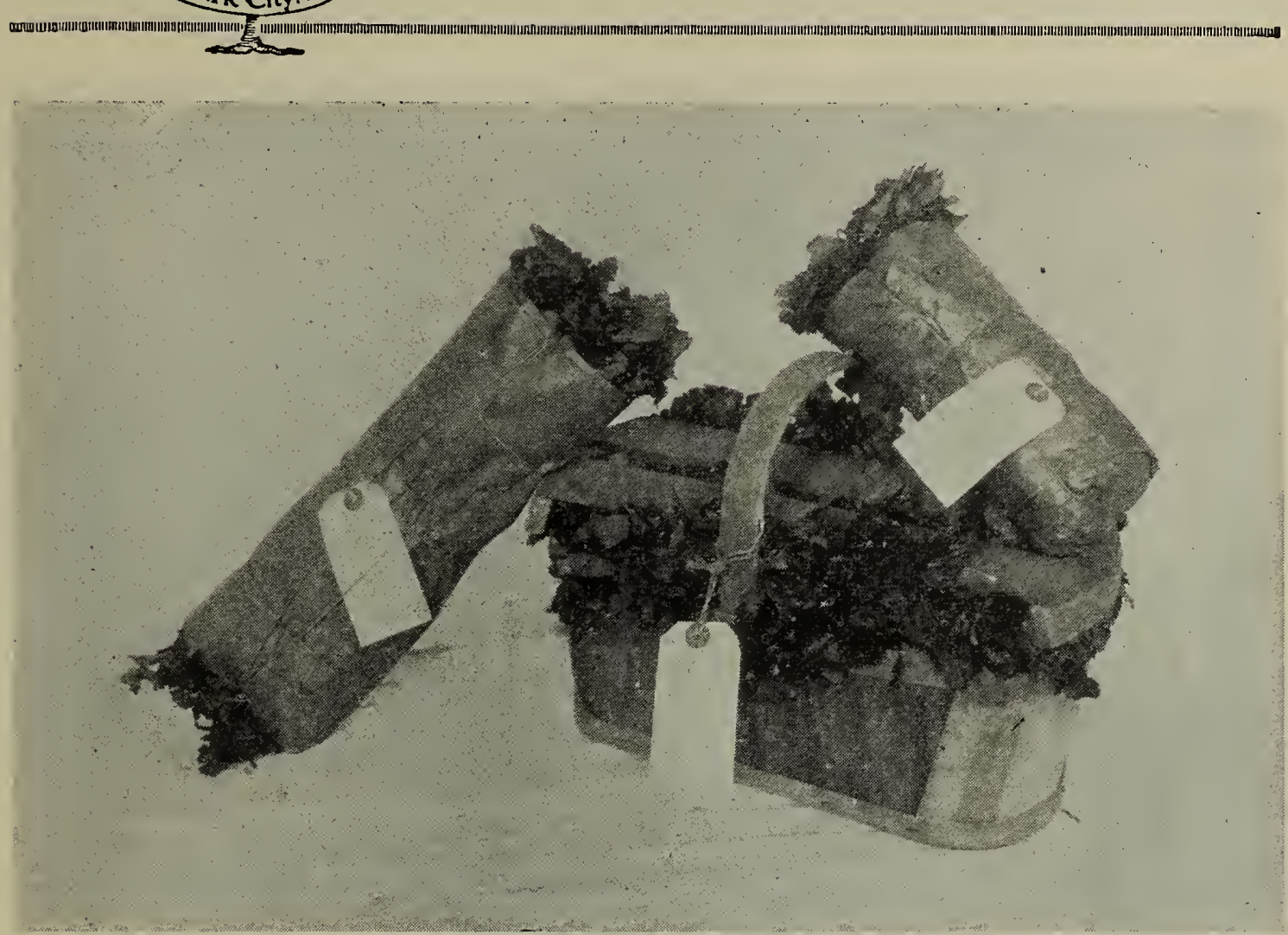

William P. Stark plants packed for Parcel Post and Express shipment. Quick delivery on rush orders to all parts of the United States.

and the leaves and stems at the top of the ground are always more or less green; hence they can not be packed like trees.

STRAWBERRY PLANTS SHIPPED SEPARATE FROM NURSERY TREES berry plants. Plants should not be shipped until the danger of hard frosts is past.

\section{GUARANTEED DELIVERY}

We guarantee that your plants will reach your express office or post office in good condition. Most of the larger shipments go by Express. We can ship Strawberry plants by Parcel Post, and this is especially good where you live some distance from town, and have Rural Free Delivery. Strawberry plants will stand a great deal of handling and will carry long distances if they are treated properly. They are given fast service by the Express Companies, who make a lower rate on Strawberry plants than on general merchandise.

Your order should be sent in promptly. Do this just as soon as you can. We will have it checked, everything ready; then at the right time, when the Government Weather Bureau Service reports conditions favorable for planting in your section, we will take up these plants from our propagatingbeds and fill your order, shipping it to you immediately. 


\section{Stark City Strawberries}

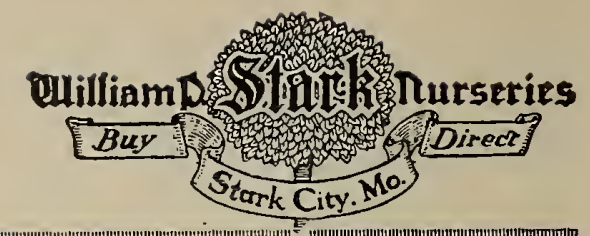

ตัต

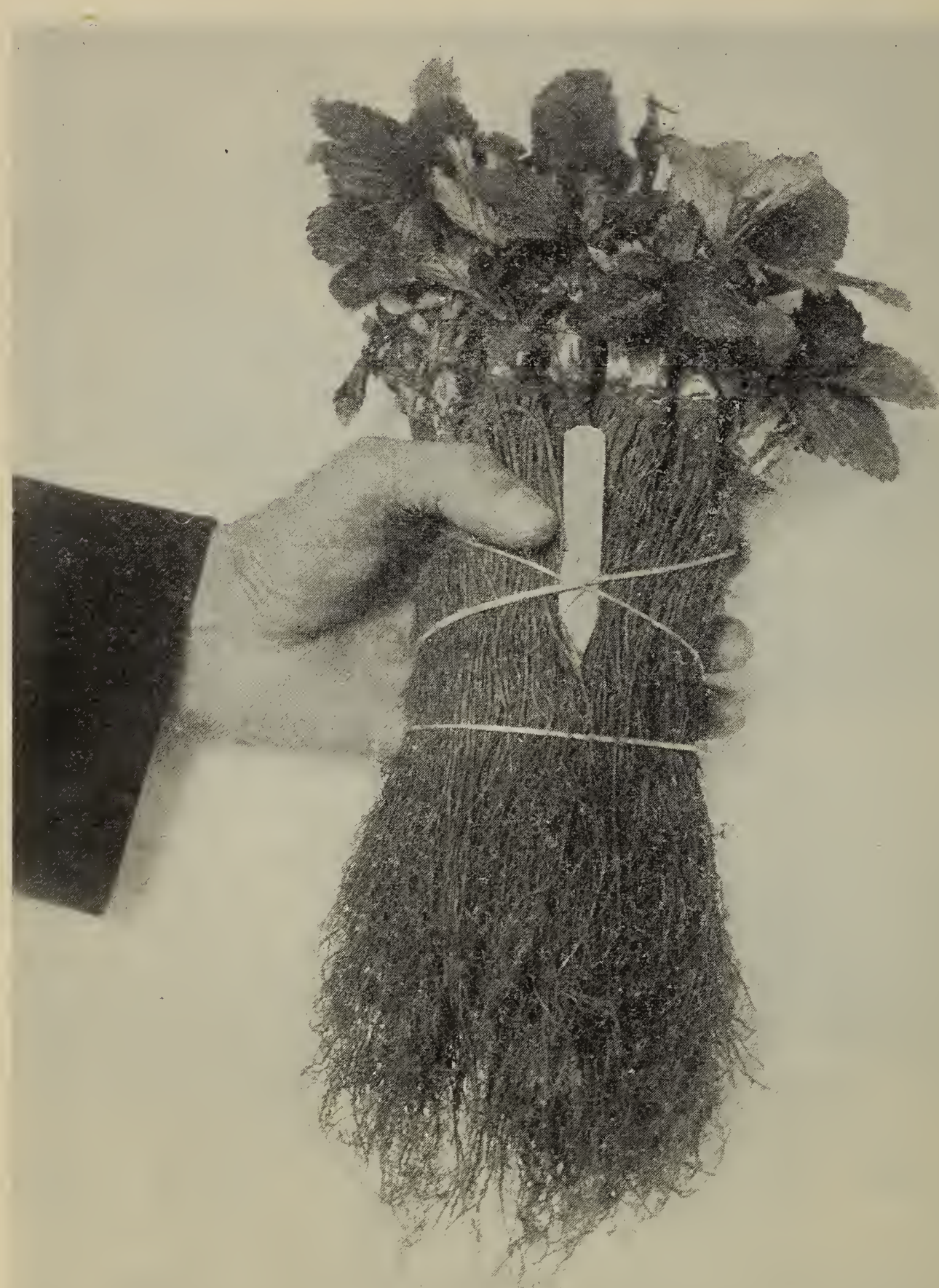

\section{Highland-Grown Plants.}

Our hardy Ozark Mountain-grown plants are propagated in one of the greatest Strawberry sections of the country. The soil and climatic conditions produce large, healthy crowns. The roots are firm and heavy. The plants are robust and hardy, and because of their great vigor are adapted to every part of the country. They succeed in cold New England and on the bleak prairies of the Dakotas. Wherever you live, you can safely buy William P. Stark Strawberry plants with the knowledge that you are getting a hardiness, vigor and productiveness that will?give satisfaction to you. We ship everywhere and guarantee safe arrival. 

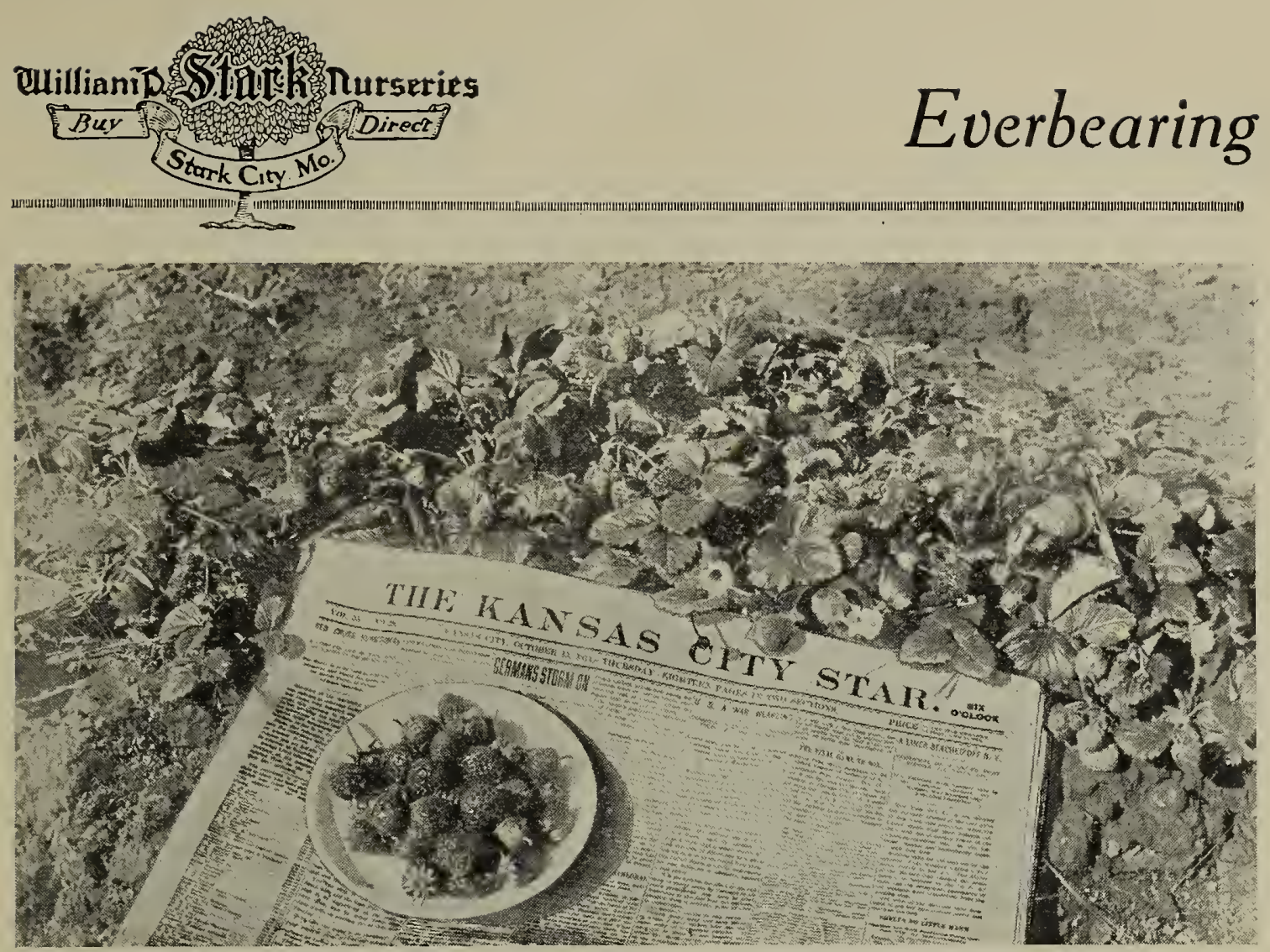

Note the date on the paper. October 15 th and plants loaded with ripe, ruddy berries Our Everbearing Strawberry plants at Stark City, Mo., bore until November 14th. 1

\section{Everbearing Strawberries.}

They Bear the First Year and Will Give You Rich, Ripe Berries Until Frost. Fruit Brings 25c lo 50c per Quart. A Demonstrated Success.

Strawberries from June to November! A few years ago that would have sounded like a fairy-tale, a horticultural phenomenon contrary to all the laws of Nature. But the Everbearing Strawberry is here in actual fact. It has been tested, tried and proved. And it has made good in both commercial and home garden plantings in widely varying parts of the country •

So many new and unsuccessful Everbearing fruits have been introduced that people have been slow to plant Everbearing varieties. The great value of the Everbearing Strawberry so far has been appreciated by only a few growers--but these growers are reaping profits far in excess of the returns from the old-time standard varieties. The "Doubting Thomases" have only to try and see these wonderful berries to become as enthusiastic as those who are now growing them so successfully.

The genuine Everbearing Strawberries are not a variable "sport," but a distinct race that are dependable and will produce berries all summer long. The first crop is borne early in the season, at the same time as the standard or June-bearing varieties. Then there is a continuation of blooming, producing ripe fruit throughout the summer if conditions are favorable. Following this is another especially heavy blooming period in the late summer, and a large crop follows until severe frosts come. You pick strawberries for four to five months, instead of one.

A severe drouth or neglect during the heat of mid-summer will check the fruiting of the Everbearing varieties, just as it checks the fruiting period. 


\section{Everbearing}

of the standard varieties; but even under neglect the Everbearing plants produce heavily in the late summer and autumn. Drouth that cuts off the crop for the year on common or standard varieties simply checks the Everbearing berries, and they come on as productive as ever with the first rains, producing new blooms and starting another crop.

We especially recommend the Everbearing varieties, Americus and Progressive, to our customers, because we have tried them thoroughly and know from experience that they are an unqualified success.

\section{FRUIT BRINGS} HIGH PRICES
They are not only most desirable for home use because you can enjoy fresh strawberries on your table all summer and fall, but they should be planted commercially because they bring as high as 50c a box in the fall at the very time when there are no berries or small fruits on the market.

You should plant some of the Progressive and Americus Everbearing Strawberries described on the succeeding pages this very spring. Don't lose another year's time. Plant now and have strawberries this coming summer and fall.

\section{SUCCEED}

EVERYWHERE

The Everbearing varieties grow and thrive on any soil where the standard varieties do. They are cultivated and handled in the same manner. Give them the same attention you do other Strawberries and you will be rewarded with deliciously flavored berries and lots of them until snow flies.

BEAR THE Everbearing Strawberry plants set out in the spring will FIRST YEAR produce fruit the same season; but, if you wish them to make a heavy fruiting row for new plants the following year, it is advisable to pinch off the first lot of bloom. Plants are so determined and profuse in their bearing habits that they will not only produce berries the first season they are planted, but they will make runners, and these new runners will produce berries the same season in which they are formed.

NO FAILURES FROM FROST

If frosts kill the first bloom, the plants will put out a second lot of bloom. In fact, there are white blossoms, green fruit and ripe fruit on plants at the same time nearly all season long, as on the orange trees in California. We had berries in our own testing-beds at Stark City until the 14th of November. Think of it! Fresh, ripe strawberries almost until Thanksgiving. They cost very little to raise, and will stand a great deal of mistreatment and neglect.

STRONG-GROWING HEALTHY

of Strawberry soil.
The foliage of the Everbearing varieties is unusually healthy. They are especially resistant to rust, hardy, vigorous in every way; succeed on all types

\section{\$7.20 PER CRATE}

A neighbor of ours said on November 9th last: "I am selling strawberries right now to the city grocers at $\$ 1.20$ per gallon, or $\$ 7.20$ per crate. The Progressive is O. K. I am going to set out five acres of these in the spring." 


\section{Everbearing}

Mr. J. Vincent Bailey, Superintendent of Horticulture at the Minnesota State Fair, was like a great many other skeptics, but at the Minnesota State Horticultural Meeting last winter became convinced of the value of Everbearing Strawberries, and tried them. He says: "I was most skeptical, and did not believe from hearsay the berry would bear steadily through summer and fall; but I have raised and marketed the Everbearers one entire season, and must admit they seem to have proved themselves in every way. Those I have raised are fairly large as marketable berries go, very near scarlet in color, and the flavor suggests the wild strawberry. I would judge that a greater income might be gained from an acre of these berries than from an acre of the ordinary kinds if both were sold at the same market price. We received 50c a quart for all we could grow."

Mr. E. H. Favor, editor of The Fruit-Grower and Farmer, says: "Late in August, 1913, it was my good fortune to visit a forty-acre field of Everbearing Strawberries in full bearing. Although I had heard much of this new berry, I had been inclined to believe that fall crops of berries were produced more by the manipulation of the fields than by the actual nature of the plants. But when I saw this field, in August, with crates being picked for market and still other crates coming on in the green berries, I was fully convinced that Everbearing Strawberries were a fact. Personally, I am enthusiastic about them. Every grower, large or small, should plant some."

PAID HIM $37 \frac{1}{2} \mathrm{c}$ PER QUART

On August 17th, Mr. Willard B. Kille, of New Jersey, wrote us that from $3 / 4$ of an acre of Everbearing Strawberries, he had picked, from the 19th of June to August 17th, 800 quarts of berries, besides picking 24 crates as a spring crop.

A later letter from Mr. Kille, dated September 16th, 1914, says: "I have picked nearly 1,200 quarts of Everbearing Strawberries since July 1st.

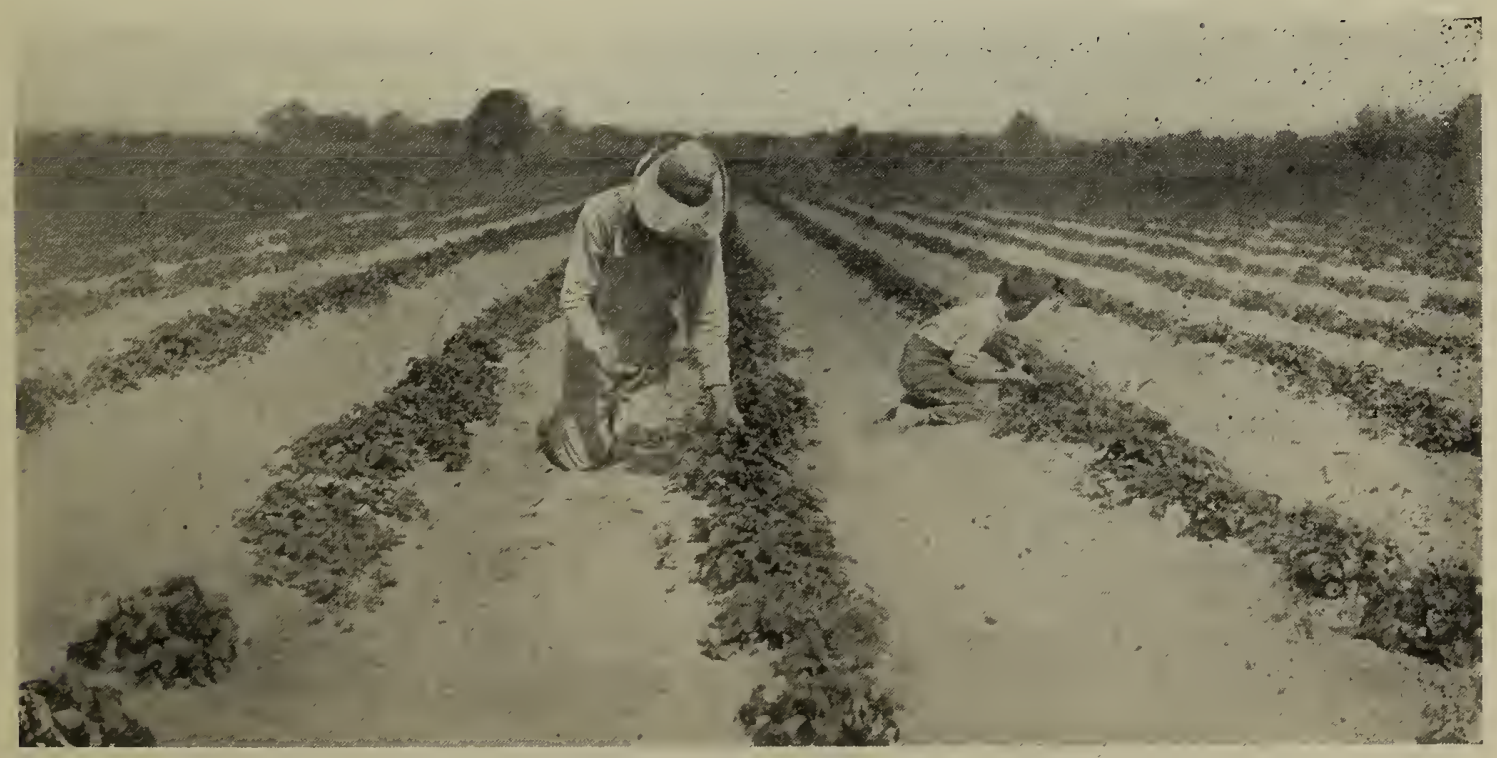

Willard B. Kille, of New Jersev, picking Everbearing Strawberries in September. He received $371 / 2 \mathrm{c}$ per quart wholesale for them in the Philadelphia markets. 


\section{Everbearing}

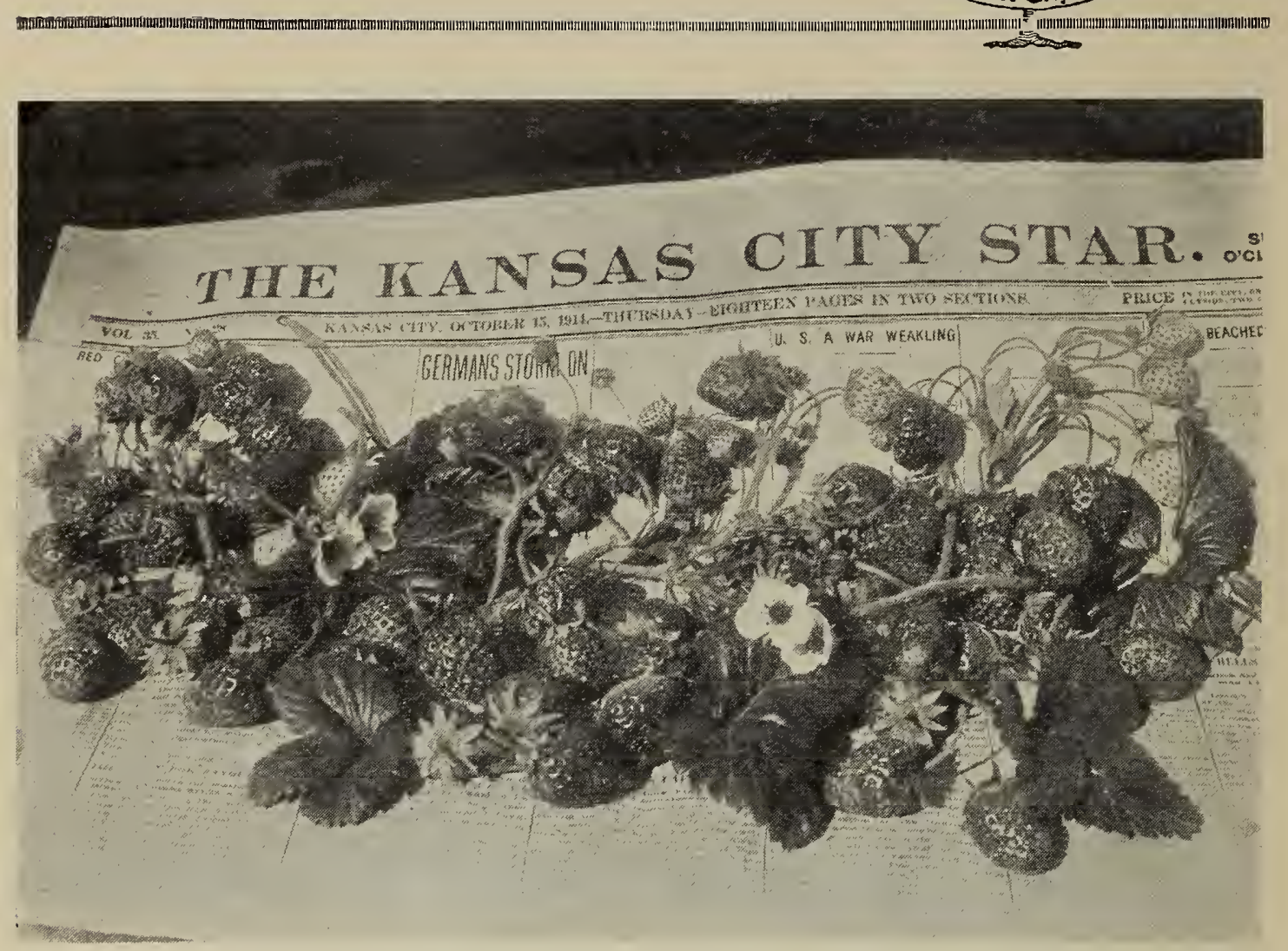

Blossoms, green fruit and berries all at the same time in October on Americus Everbearing plant. Mr. W. R. Nelson, Publisher of the Kansas City Star, wrote us November 19th, 1914; "The strawberries surpassed tha expectations aroused by your advance information on the subject. They are all that the heart could wish, and I am ready to come forward and testify that your vines bear summer and autumn alike."

Have picked over 8 crates (32 quarts each) this week. My berries sold in Philadelphia this morning for $371 / 2$ c per quart wholesale."

AMERICUS (S) Americus is the best quality of the wonderful new race (Everbearing)

berries from very early in the season until the hard frosts come in the fall of the year. Berries are bright red, medium to large size, roundish, heart-shaped, very attractive in appearance, not as dark red as the Superb, but unusually high flavor, very rich aromatic, being superior to the Marshall. The Americus is the best-flavored of the Everbearing Strawberries, and you can have them now for months, where formerly the season was but a few weeks long. It is a good shipper and will hold up as well as Senator Dunlap and nearly as well as the Warfield. It is said by some not to be as good a shipper as the Progressive, but our experience is that it will stand handling and is as good a keeper as the Progressive, which, with its excellent quality, makes it one of the best Everbearing varieties for home use, as well as a profitable commercial berry. It begins bearing the first berries with the extra early varieties, but this first heavy crop ripens over a long period of about six weeks, and continues to bloom and ripen fruit throughout the summer. This first heavy crop can be delayed by picking off the first lot of bloom, bringing it to maturity just after the late varieties are gone. 


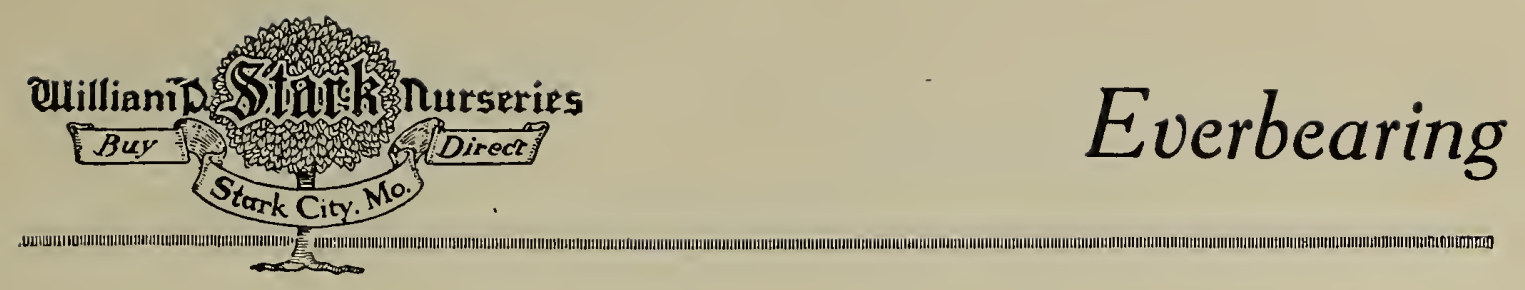

The plants do not grow tall, but they have a wonderful strength and resistance, and will withstand a great deal of hardship. Dry weather does not affect them as it does other varieties, and, if the bloom is killed by frost, they will put out a second lot and go right on bearing. It is a moderate plant-maker, but unusually good for an Everbearing berry; will make about as many runners as the Bubach. Shoots also put out from the main central plants, forming a crown or stool, so it is naturally adapted to cultivation in stools or crowns as well as matted rows. It thrives best on strong soils, such as fertile loams and clay. They will do well on light sandy and rocky soils, but the berries will not average so large. The berry clusters are borne on long, stout stems which hold the fruit from the ground, keeping it clean. It has staminate or perfect blooms and does not have to be planted near other varieties for cross-pollenation.

The Americus is one of the best Everbearing plants where you want berries the same season you set them out, as they are very good plant-makers and the fruit will not be at the expense of the new plants for next year's crop. One hundred plants should make 75 to 100 quarts of berries the same season they are planted, and these sold at the fancy out-of-season prices would make you a large profit the first season.

Per bunch of 25, $\$ 1.00$; per $100, \$ 3.00$; per $500, \$ 10.00$; per $1,000, \$ 17.00$.

PROGRESSIVE

(S) (Everbearing)

$\mathrm{T}$ h e Proive is considered by many to be the best all-around Everbearing Stra wber ry. It is a cross between PanAmerican and Senator Dunlap, and the fruit closely resembles the Dunlap in many ways. It is medium size, rounding, tapering slightly toward an oval point, very uniform, an ideal Strawberry shape. The surface is smooth, lustrous, and a dark, brilliant red color, which extends to the center of the berry. It is good quality,

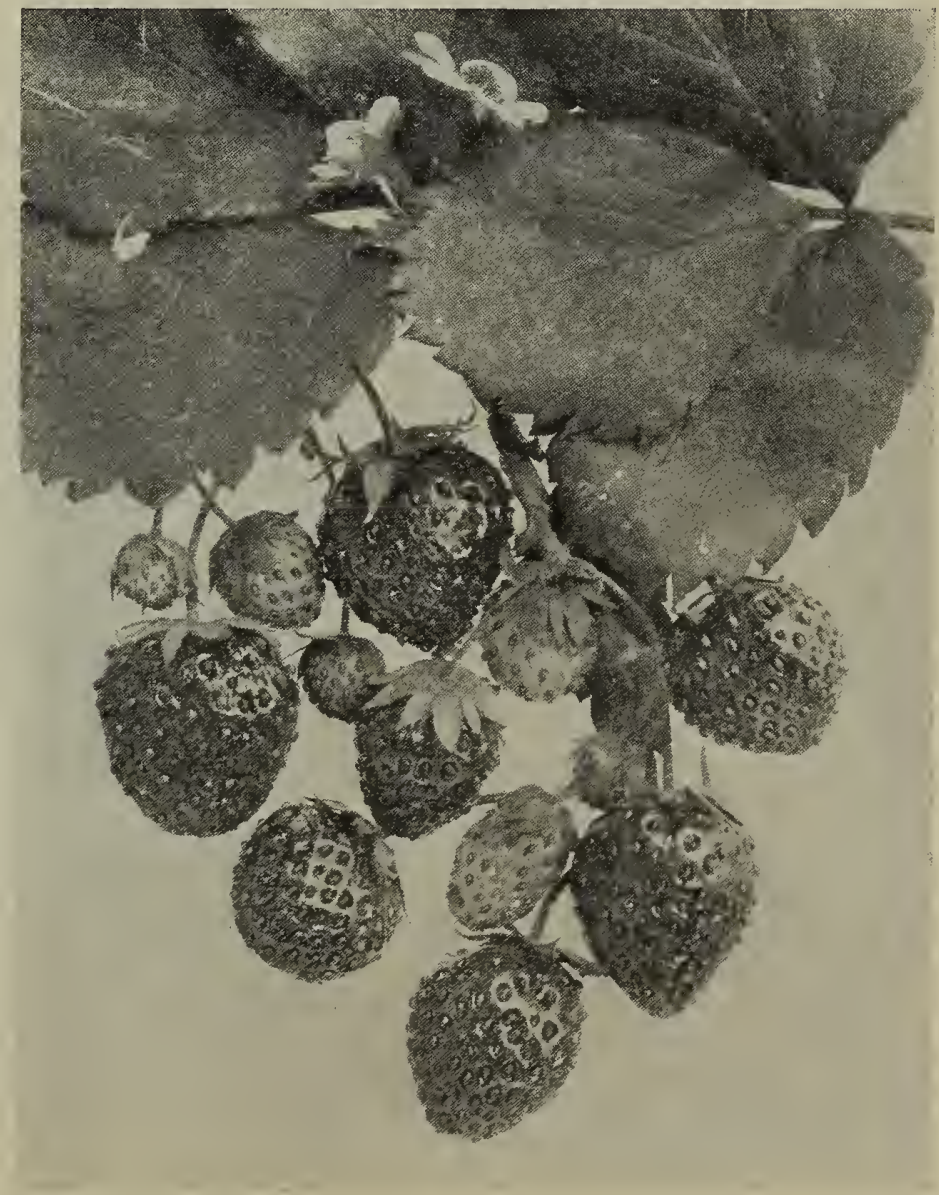

Progressive-Everbearing-Expensive $\mathrm{p}$ o $\mathrm{t}-\mathrm{g} \mathrm{r}$ o $\mathrm{w}$ plants are no longer needed in order to get quick results Everbearing plants produce the same summer they are set out and are cheaper than pot-grown plants, and bear throughout the entire season. 


\section{Everbearing}

mild and pleasant. The general appearance of the Progressive is unusually attractive, being of the beautiful dark Strawberry type that appeals to the markets everywhere. The flesh is firm, smooth, velvety and stands handling and shipping well. As a keeper and a commercial berry it will hold up better than Senator Dunlap and nearly as well as Warfield. Like its parent, it is good for canning and preserving, but the large quantities of berries that are produced out of season are too good and too valuable to be used for canning purposes.

The Progressive is an enormously productive berry. The first or June crop, which lasts over a period of about six weeks, will equal that of the standard varieties. Single plants often carry 100 to 150 blossoms and fruits at one time. The new plants produce the same season in which they are formed; in fact, the little runners sometimes put out bloom before they are well rooted. If a heavy fruiting row is desired at once, this first bloom can be pinched off and a good fruiting row developed and a good crop matured the fall of the same season in which the plants were set. The Progressive, like the Americus, has a staminate or perfect bloom and is a good plantmaker. Their success as commercial berries depends upon this ability to produce new runners, because a commercial variety must develop a good fruiting row. They are not a novelty, but thrive under the same care and the same conditions as any standard variety. They do not have to be nursed and coddled to get results. The Progressive plants are hardy and will withstand a great deal of freezing and drouth. In our testing-beds we continued to pick berries after several severe frosts, and it has always taken a hard freeze to stop them bearing for the year.

The Progressive, like the Americus, will thrive on sandy and rocky soil, but the berries will not average large unless the fertility of the land is kept up. They will produce en ormous quantities of berries, which naturally calls for an abundance of plant food. The largest berries can be grown on fertile loams and clay soil.

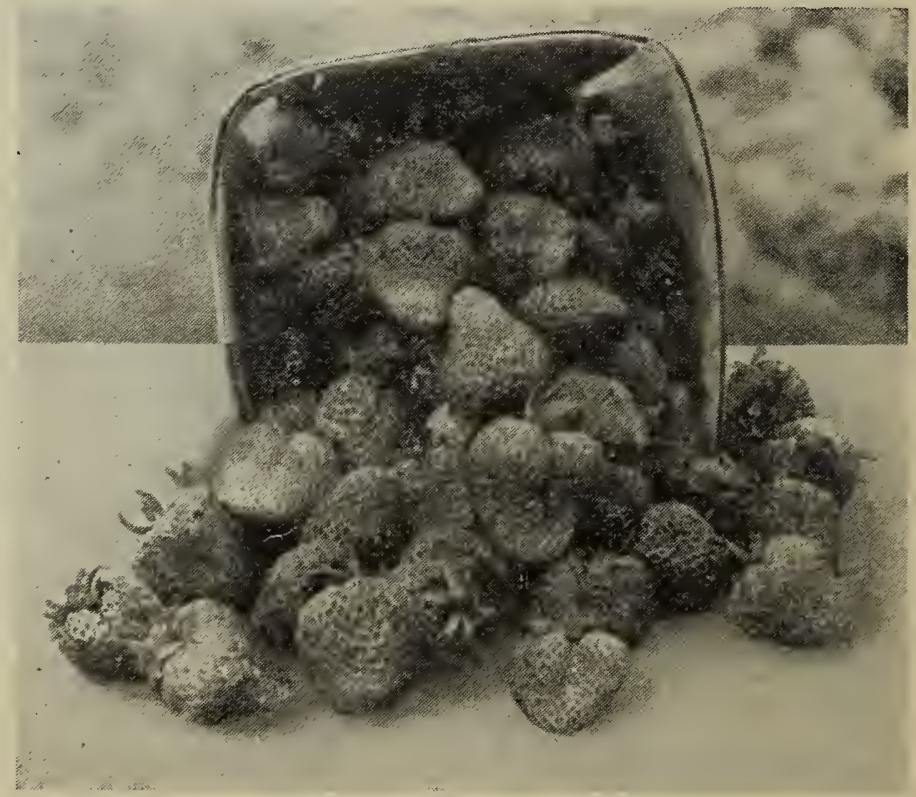

Aroma-The great Market Berry. About 1,500 carloads, worth from $\$ 1,200$ to $\$ 1,250$ per car, go out of this Ozark country each season, beginning as early as May 10th. From 300 to 400 cars are shipped by growers within a few miles' radius of our nurseries every year. The Aroma beats them all as a money-maker. 


\section{Standard Varieties}

stark City. Mo

NOTE-Varieties marked "S" are "staminates" and have perfect blooms. Those marked "P" are "pistillates" and have imperfect blooms. Pistillate varieties should be planted near staminate varieties to get thorough cross-pollenation. Large fields of staminate varieties can be planted alone. Do not plant pistillate or imperfect-flowered varieties alone, but for every three or four rows of pistillate varieties there should be a row of a staminate variety alongside.

$\begin{array}{ll}\text { AROMA (S) } & \begin{array}{l}\text { Aroma is the } \\ \text { most profit- } \\ \text { (Late) } \\ \text { able and de- }\end{array}\end{array}$ pendable Strawberry grown. Very large and roundish,

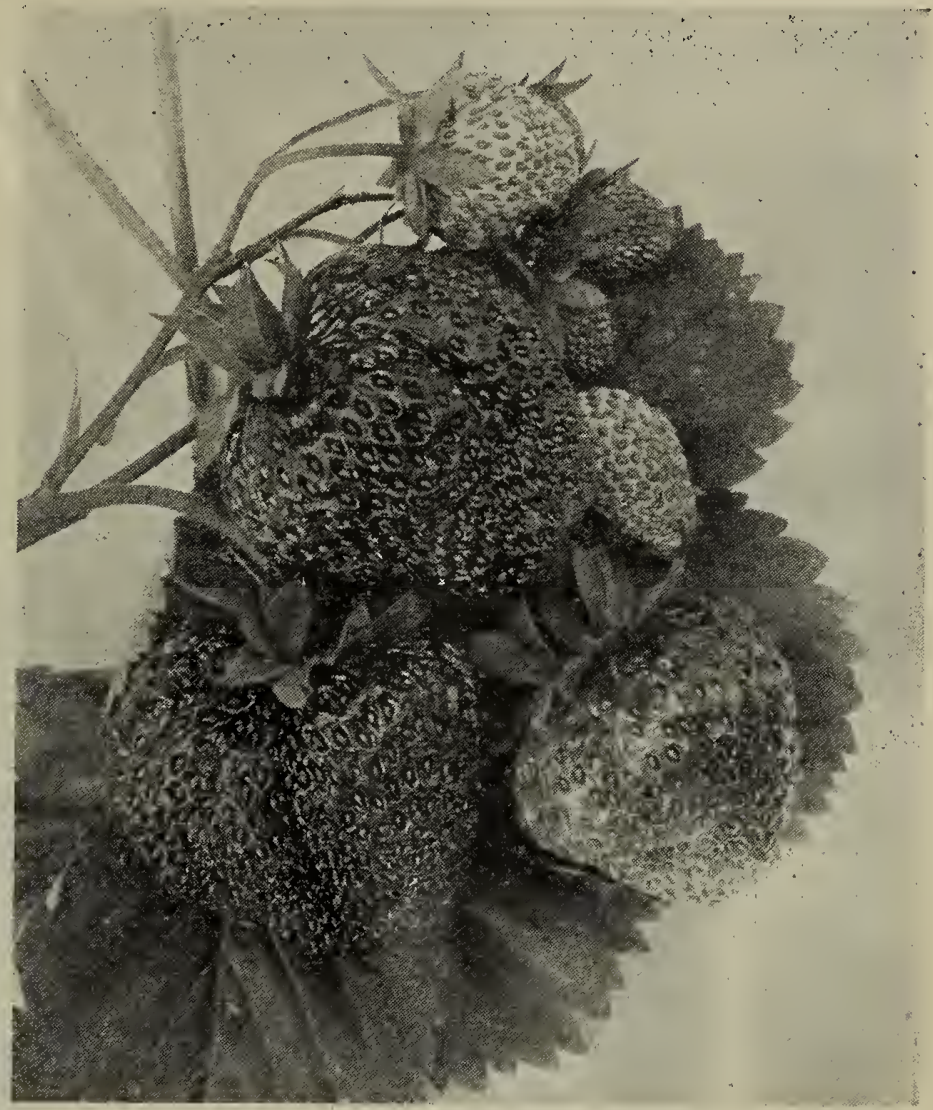

Aroma-The best all-around Strawberry for market home growing, canning, etc. Popular everywhere. having the ideal Strawberry shape. Smooth surface, medium size calyx. It is a bright scarlet red, glossy, smooth surface, with prominent yellow seeds like specks of gold in crimson wax.

The flavor is deliciously aromatic, hence the name-Aroma. The flesh is firm and velvety, with a smooth and solid texture, withstanding a great deal of handling; its rich, sprightly juiciness and beautiful appearance make the Aroma one of the most alluring berries for home use and for market. The Aroma is popular everywhere and is the best shipping Strawberry known. Hundreds of carloads are shipped from this Ozark country each year. They go to every part of the United States: Denver, Minneapolis, Chicago, Buffalo, New York, and the South. It is difficult to imagine a more satisfactory, more dependable, all-around Strawberry than the Aroma. There may be one some day-if there is, we will tell you about it.

The Aroma is a splendid canning and preserving berry; retaining its bright color and spicy, rich flavor. It is the ideal berry for home use, because it does well on any soil, and of ten thrives where many other varieties can not be grown.

The plants are very strong, vigorous growers with an open, spreading crown that lets in the sun, thus preventing rot and giving the berries a beautiful even color. The leaves are long and broad with a deep green color, 


\section{Standard Varieties}

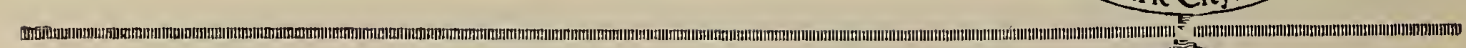

and it is unexcelled as a pollenizer for pistillate varieties. It is a good plant-maker, producing just the right number of plants for a good fruiting row: It is a late bloomer, hardy, and the berries ripen through a long fruiting season, holding their size throughout the season, coloring evenly. The surest-cropper, and bears off years when other varieties fail.

The Aroma is the king of the Strawberries and $\mathrm{h}$ as largely. supplanted the wellknown Gandy, being three times as productive, and it is suited to a greater range of soils and climates and has greater adaptability. They will grow anywhere Strawberries can grow. In this Ozark country the rougher and rockier the land, the bigger the berries produced. Land that is too rocky for farming often produces as high as $\$ 200$ to $\$ 300$ per acre net on one crop. It does well on sandy land and on clay land. You don't have to spray them, and they are not affected with rust. It is the great

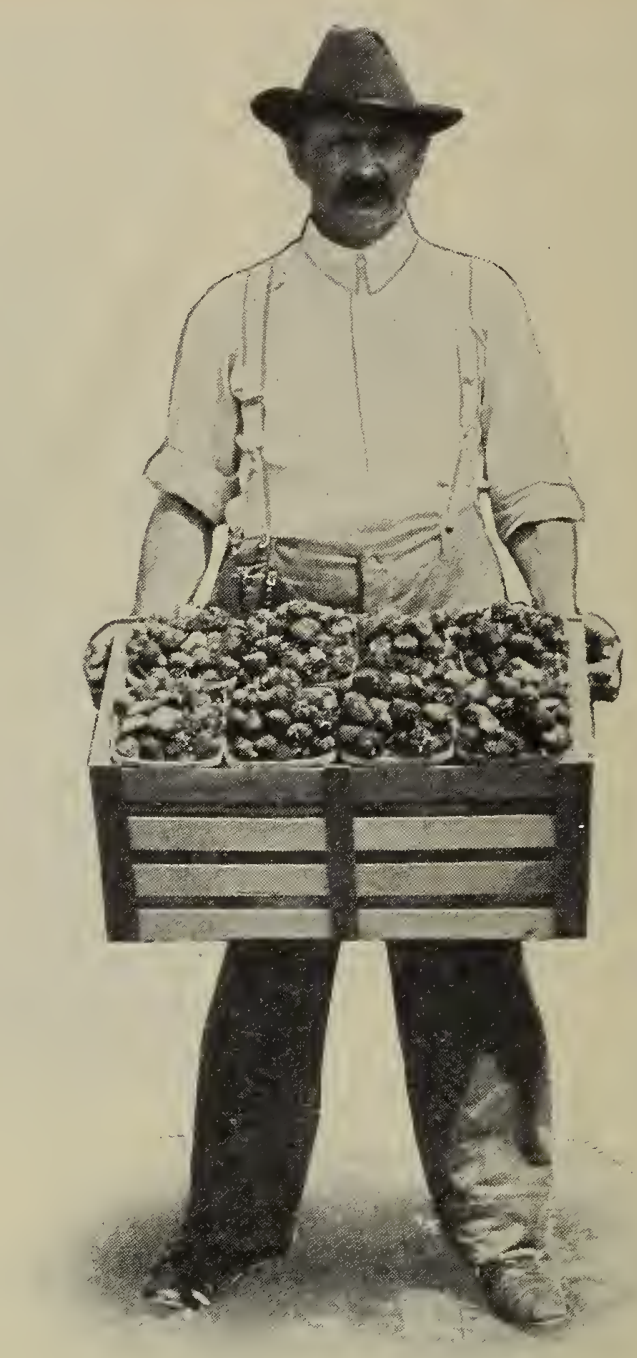

Mr. Albert Adams, a Newton County neighbor of ours, whose Aroma Strawberries paid him $\$ 2,400$ from $51 / 2$ acres in 1914, and $\$ 2,300$ in 1913 . Mr. Adams now owns 80 acres of well-improved land, with a good house and barn, bought mainly with his proceeds from Aroma Strawberries, which are paying him at the rate of $\$ 400$ per acre. Aroma is the great profit-maker. favorite in warm and in cold sections because of its ability to stand shipment, and the most popular variety in all the commercial sections of the central United States and in the subtropical countries like Cuba and Mexico. Ninetynine cars of berries out of every hundred raised in this section are Aroma. It responds gratefully to the care and attention of the progressive Strawberrygrower, and at the same time it yields a profit to the careless man who will not cultivate his beds as he should.

Aroma combines all of the good qualities and has no weaknesses-it is the great business berry.

"This variety has the great advantage of shipping exceedingly well and presenting a good appearance."-Agriculiural Experiment Station, Bulletin 113, University of Missouri.

Per bunch of 25, 30c; per 100, 70c; per 500, $\$ 2.25$; per 1,000, $\$ 4.00$. 


\section{Standard Varieties}

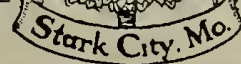

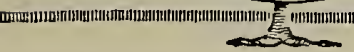

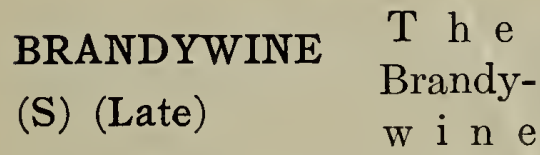

is a large to extra large, roundish berry. A deep blood-red color. Flesh is bright red with prominent attractive yellow seed. It has a peculiar individual high flavor, juicy, briskly sub-acid, very good and firm.

The plant is vigorous, productive and hardy both in the North and in the South, being especially suited to conditions on the Pacific coast, Cuba, Bermuda, and Florida. It $\mathrm{t} h \mathrm{r}$ ives under all conditions of soil and climate, and is very productive.

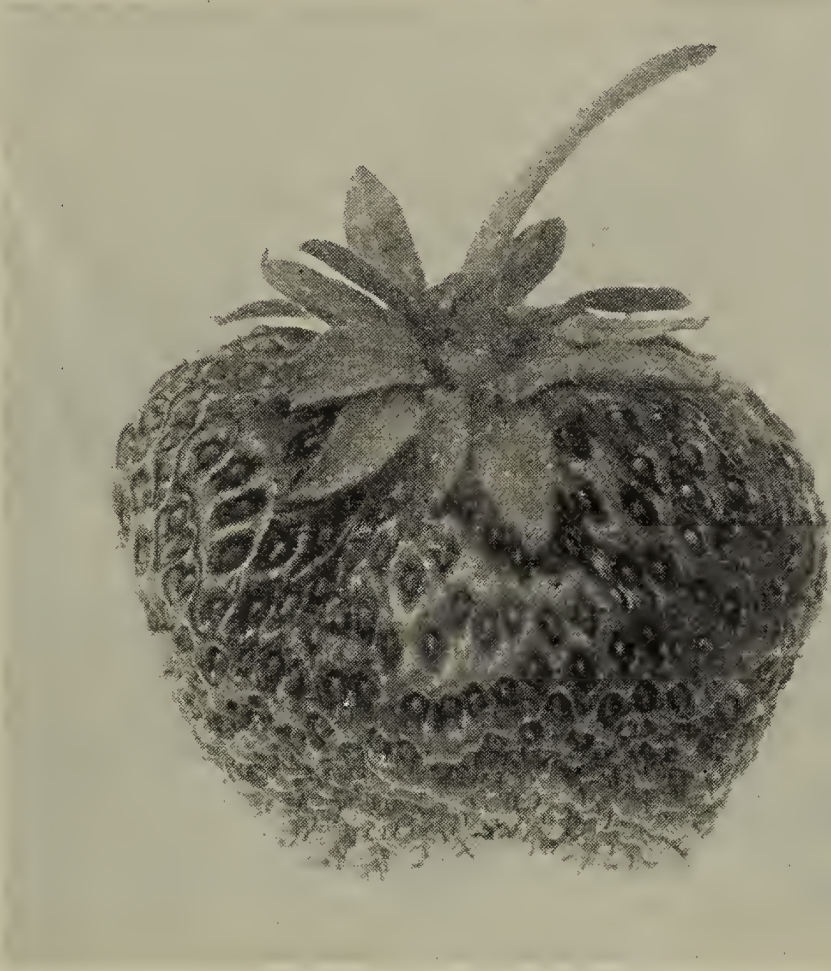

Bubach-One of the largest strawberries grown. A prime favorite everywhere. Brings high prices.

It is especially popular for home use and with the commercial grower as a market berry. It is also an ideal canning berry, owing to its dark red color and high flavor.

Per bunch of 25, 30c; per 100, 70c; per 500, $\$ 2.25$; per $1,000, \$ 4.00$.

\section{BUBACH (P)} (Mid-Season)
The Bubach is an old favorite of thirty years' standing, and is one of the largest Strawberries grown, a thick, broad, irregular berry, sometimes wedge-shaped and sometimes rounding. Bright scarlet red color, which extends through to the center of the berry. In quality it is very good, juicy, sub-acid; flesh fairly firm. Its remarkably fine appearance, combined with its good quality, has made it very.popular and it is particularly recommended for home use and nearby markets. It is famous for its productiveness and large size, as well as beautiful color. The plants have retained all of their old original vigor and produce large crops of big berries. It is a moderate plant-maker; free from rust; vigorous, and appeals to buyers everywhere as do few berries, and always tops the market.

The plants are dark, glossy green of a spreading habit; short leaf and fruit stem. Thrives best on fertile loam, clay, or black muck soil.

"Without doubt one of the finest in regard to size and appearance of fruit, productiveness, and good foliage."-Central Experimental Farm, Ottawa, Canada, by W. T. Macoun.

Per bunch of 25, 35c; per $100,80 c$; per 500, \$2.75; per $1,000, \$ 5.00$. 


\section{Standard Varieties}

CARDINAL (P)

(Mid-Season)

The Cardinal is very productive, medium to large size berry, round, tapering to an oval point, sometimes flattened or wedge-shaped. Beautiful rich glossy red, from which it gets its name-Cardinal.

Flesh bright red and juicy. Above average quality, with a brisk, sprightly flavor.

The plants are vigorous and enormously productive, the fruit ripening throughout a very long season. Bloom is frost-resistant.

Per bunch of 25, 30c; per 100, 70c; per 500, $\$ 2.25$; per 1,000, $\$ 4.00$.

CHARLES I. (S) Charles I. is a very promising early variety for com(Early)

mercial and home use, large regular-shaped berries, fine appearance, extra good color; extra good quality for an early berry, firm flesh, ripens a little after Michel, but has proven to be more productive; a very profitable berry for the first part of the season. Plants strong, vigorous, hardy.

Per bunch of 25, 35c; per 100, 80c; per 500, $\$ 2.75 ;$ per $1,000, \$ 5.00$.

CHESAPEAKE (S)

(Late)
Chesapeake is one of the most widely planted berries grown, averaging larger size than the Gandy. A uniform round berry. Dark rich scarlet color. Flesh

light red, good quality.

The plant makes a moderate number of runners. Very productive, rust-proof, withstands drouth and resists late frost.

It should be well cultivated in order to produce enough plants to make a good fruiting row. It is a late bloomer, producing a large number of blooms, and the fruit retains its size to the end of the fruiting season.

Per bunch of 25, 35c; per 100, 80c; per 500, $\$ 2.75$; per 1,000, $\$ 5.00$.

CLIMAX (S) The Climax is a very good medium size conical berry, with (Early) a beautiful bright glossy red surface. Very delicious flavor, rich and juicy. The fruit is especially attractive on the market, being popular with the commercial growers and retail merchants. The flesh is firm, making it a good shipper.

The plant is hardy, strong, vigorous, upright grower; rust-resistant, with a wide range, succeeding in practically all soils and climates.

Per bunch of 25, 25c: per 100,60c; per 500, $\$ 2.00$; per 1,000, $\$ 3.50$.

CRESCENT (P) The Crescent is one of the oldest and best-known Straw(Early) berries, medium size, generally wedge-shaped, but often roundish, tapering to a dull point. The Crescent is a bright red, deliciously tart Strawberry, with firm, close-grained, solid flesh. It keeps well in storage. Its brisk tartness and firm flesh make it one of the best shipping and canning berries grown.

The plants are vigorous, making numerous runners. It is especially valuable because of its attractiveness and because it succeeds everywhere, withstanding neglect and responding readily to cultivation. It is a medium size plant.

Per bunch of 25, 25c; per 100, 60c; per 500, $\$ 2.00$; per 1,000, \$3.50. 


\section{Standard Varieties}

Stark City. Mo.

DOUGLASS (S) The Douglass is a medium size berry, glossy red, coloring (Mid-Season)

evenly all over. Very satisfactory berry for all purposes.

A good shipper. The plants are very thrifty, with dark green foliage, making a heavy fruiting row. Very productive and drouthresistant, ripening about the same time as Haverland and Senator Dunlap.

Per bunch of 25, 35c; per $100,80 \mathrm{c}$; per 500, $\$ 2.75$; per $1,000, \$ 5.00$.

EVENING STAR Evening Star is a large, uniform roundish to wedge(S) (Late) shaped berry with fine light crimson color. Flesh light red and very firm. A very pleasant sub-acid berry, combining the shape of Gandy with the dark red color of Aroma. Good shipper and a splendid berry for all purposes.

The plants are very large and vigorous with large leaves. It makes a great many plants, forming a heavy fruiting row; very productive; withstands drouth. It is planted everywhere, being as universally grown as the Gandy. Per bunch of 25, 30c; per $100,70 \mathrm{c} ;$ per $500, \$ 2.25 ;$ per 1,$000 ; \$ 4.00$.

FENDALL (P) Fendall is a large roundish to roundish wedge-shaped berry, (Mid-Season) uniform size and smooth glossy crimson color, with long stems and large caps. Greenish-colored seed. Fine-flavored and a good shipper.

Plants are luxuriant, light green color, productive, thriving everywhere, moderate plant-maker. Berries ripen over a very long time.

Per bunch of 25, 35c: per $100,80 \mathrm{c}$; per 500, $\$ 2.75$; per 1,000, $\$ 5.00$.

GANDY (S) Gandy is a well-known standard of comparison, from medium (Late) to large size, roundish, oval berries, slightly flattened at the tip, deep red to a scarlet color with bright red flesh. The Gandy is an excellent berry with a brisk tartness that is very pleasant. This combination, with its pleasing appearance, makes it one of the best selling berries on the market. Flesh is very firm, so that the berry stands shipping well.

The plant is moderately vigorous, and makes a fair number of runners. Does well on all soils except those of a dry, sandy nature. Should be planted on fertile soil. Succeeds in every part of the country, and before the Aroma became so well known, it was the universal favorite among $\mathrm{Str}$ a w b e r $\mathrm{y}$ -

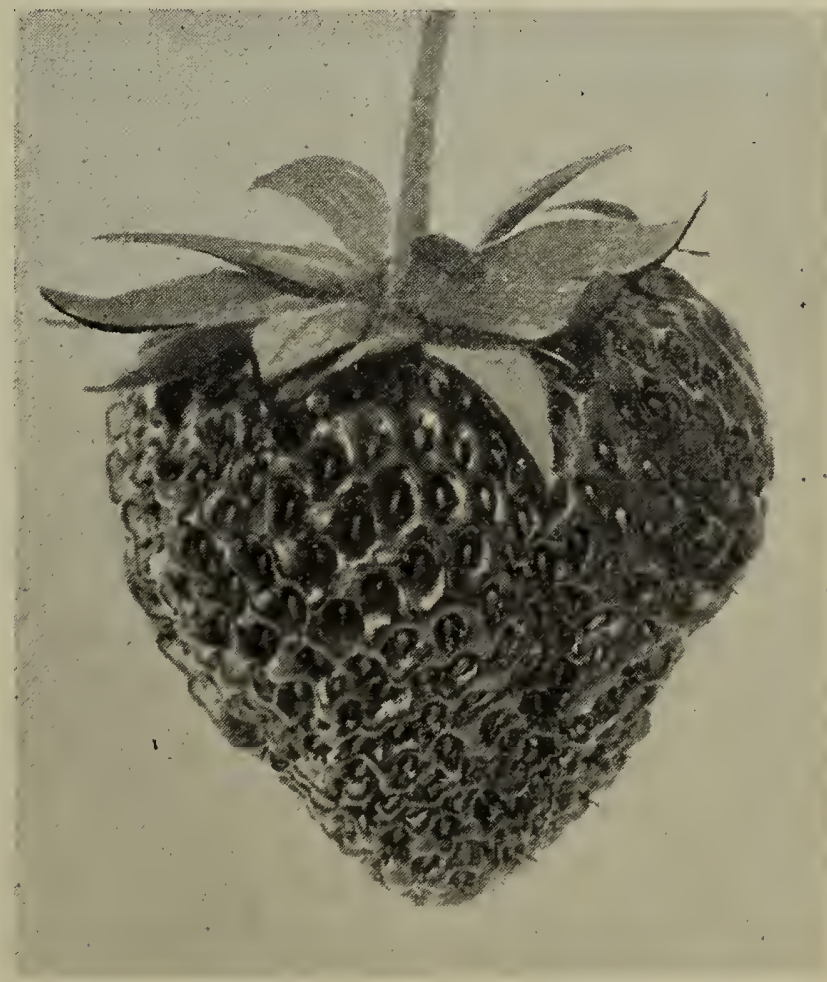

Gandy-One of the best known. Standard. A good seller. 


\section{Standard Varieties}

growers. It is still planted very extensively, and is a very profitable berry.

Per bunch of 25, 30c; per 100, 70c; per 500, $\$ 2.25$; per $1,000, \$ 4.00$.

$\begin{array}{ll}\text { GLEN MARY (S) } & \text { The Glen Mary } \\ \text { (Mid-Season) } & \text { largest straw - }\end{array}$ berries, regular, rounded to wedgeshape, a deep red at the base of the berry with a lighter red at the tip, seeds not very prominent, flesh bright red. Juicy, firm, good quality. A standard berry for market a nd one of the best for forcing indoors.

The plant is moderately vigorous, with heavy roots, which make it a good drouth-resister. It doesn't make a large number of runners, but the berries average quite largye, filling the cups rapidly.

Per bunch of 25, 35c; per 100, 80c; per $500, \$ 2.75$; per $1,000 \$ 5.00$,.

\section{HAVERLAND (Mammoth Beauty)} (Mid-Season)

Haverland-Long, tapering. Enormously productive. Fine for canning.

Haverland is one of the most popular tested varieties. Very long, regular, pointed berries, which gradually taper toward the tip, which is rounded; medium to large size; bright red color, with prominent yellow seeds; flesh light red. The calyx covers the end gracefully, giving the berry a most beautiful tempting appearance. It is as good as it looks, having a rich, juicy flavor, moderately firm flesh, especially fine for nearby markets, and, if not allowed to get too ripe, can be shipped as far as any variety. Very good for canning and preserving.

The plants make ample runners, strong, vigorous. Thrives everywhere, especially in the Northwest and the Eastern States. The blossoms are medium size; very hardy. The plants should be well mulched, as the berries are so numerous in the clusters that stems can not hold them off the ground. The Haverland bears when others fail and succeeds everywhere under all conditions of soils and climates. Berries retain their large size throughout the entire season. It has been found to be especially satisfactory for Long Island and similar locations along the Eastern Coast.

Per bunch of 25, 30c; per 100, 70c; per 500, \$2.25; per 1,000, $\$ 4.00$.

HELEN DAVIS (S)

(Early)
Helen Davis is one of the hardiest berries; above medium size; round, slightly pointed, uniform shape; dark red color, which extends to the very center of 20 


\section{Standard Varieties}
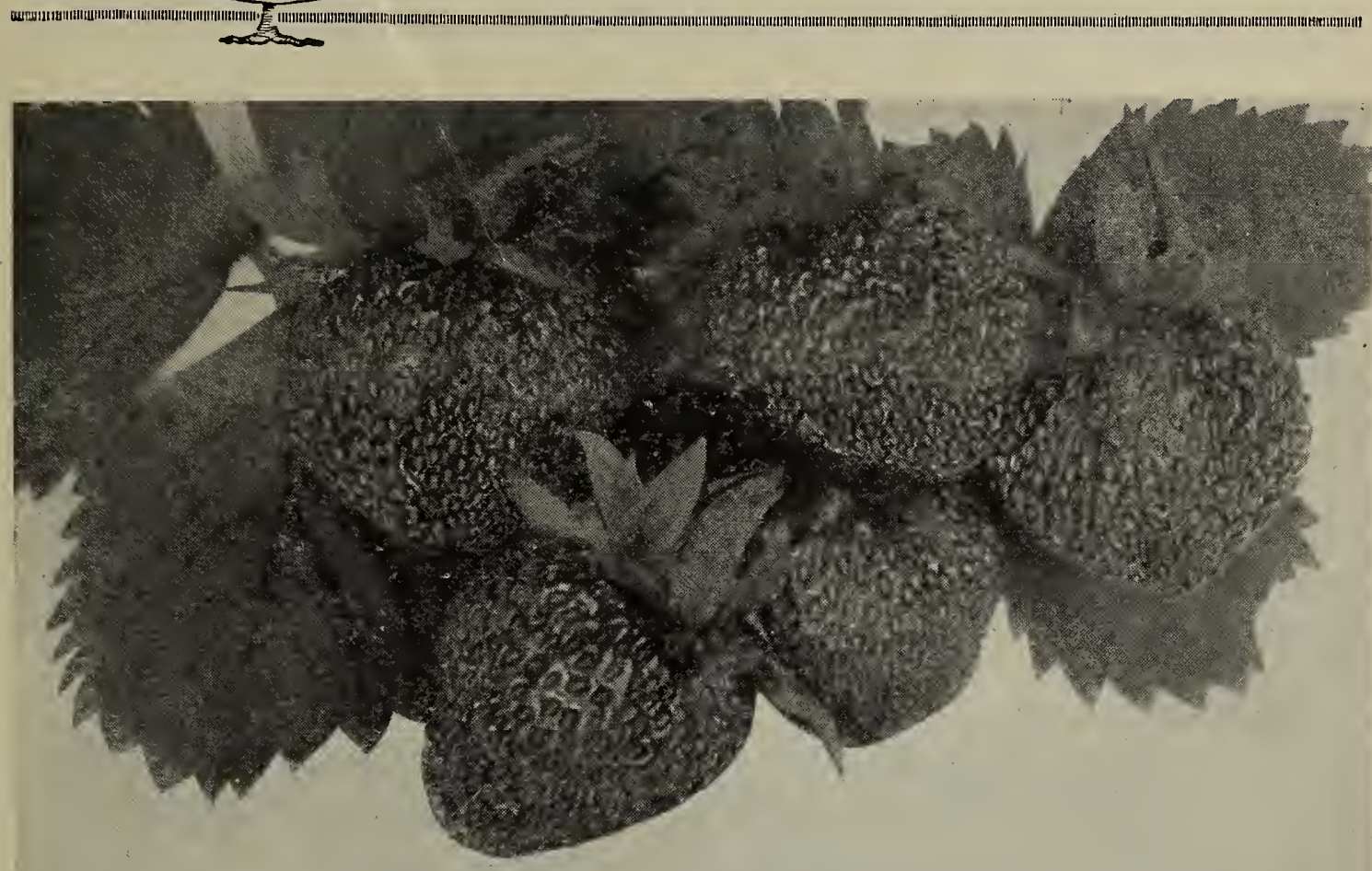

Klondike-Big brilliant berries. Sell everywhere on sight.

the berries. The caps remain bright green after picking and the berries hold up well in shipment, which, with the extra fine flavor and peculiar velvety quality, makes it a splendid berry for shipping and home use.

Plants have great vitality and thrive under very trying conditions; well adapted to the coldest regions of the Northwest and a favorite in the irrigated mountain districts. Drouth-resister, productive, and ripens throughout an unusually long season.

Per bunch of 25, 35c; per 100,80 ; per 500, $\$ 2.75$; per $1,000, \$ 5.00$.

KLONDIKE (S) (Mid-Season)

The Klondike is a very profitable berry. It was introduced in the South, and the Southern planters were the first to recognize its value; for they require a good shipper that will carry to the Northern markets. The Klondike is a large round, uniform berry, ideal strawberry shape. Beautiful rich, blood-red color. It has a delicate flavor that is neither rich nor sour, but mildly delicious and juicy. The great success of the Klondike is due to its splendid shipping quality. Few berries have been taken up so quickly and universally by commercial growers everywhere, and it is to-day planted by the hundreds of acres from the East Shore of Maryland and Delaware to Texas. It is also very popular in California and the Pacific Coast country and the intermountain States, and is a profitable variety in the Great Lake regions of the North.

The plant is vigorous, heavy grower, light green foliage, tall leaves which protect the berries from the extreme hot sun, and prevent drying out during drouth. Enormously productive, and truly it deserves the name of Klondike, for it has proven a gold mine. The plants thrive on warm, sandy soils, make a large number of runners, and the berry is as attractive as the 


\section{Standard Varieties}

Lady Thompson, if not more so; ripens a few days later and retains its size throughout the season.

"The Klondike is grown almost exclusively throughout Florida."-J. M. Brownlee.

Per bunch of $25,25 \mathrm{c}$; per $100,60 \mathrm{c}$; per $500, \$ 2.00$; per $1,000, \$ 3.50$.

LADY THOMPSON (S) The Lady Thompson is a round, uniform berry, (Early)

large size; handsome bright red, with reddishtinted seed; meat firm, solid pink color, very rich, good quality. The Lady Thompson is a splendid shipper and a good market berry, keeping well in storage, and has been widely grown for a great many years. Miost extensively planted in the Strawberry sections of the Carolinas, although generally popular throughout the South, where it is a favorite early-ripening variety.

Plants are vigorous, make a large number of runners which withstand the dry weather. It seems to thrive best during dry seasons. Lady Thompson and Klondike are the most generally planted berries in Florida and the extreme South.

Per bunch of 25, 25c; per 100,60c; per 500, $\$ 2.00$; per 1,000, $\$ 3.50$.

\section{LONGFELLOW (S)}

(Extra Early)

center of the berry. Rich, sweet, mild flavor, juicy and good.

The plants are strong, healthy, and make a good number of runners. Clean, vigorous foliage and numerous flowers.

Per bunch of 25, 35c; per 100, 80c; per 500, \$2.75; per 1,000, \$5.00.

MARSHALL (S)

(Mid-Season)

Marshall is one of the largest berries on the market, roundish, tapering to an oval point, handsome dark red color with prominent seeds; flesh a bright red. Marshall is a strictly fancy berry, rich, juicy, highest quality, deliciously sweet; one of the best berries for local market and the fancy trade, as well as for commercial shipments. Holds up well in storage.

The plants are healthy, except sometimes affected by rust; moderately productive. They are fair to good plant-makers. The berries average large, are of the very best quality and retain their size throughout the season. Very popular berry in the Middle States, and planted extensively in California and Oregon.

Fer bunch of $25,35 \mathrm{c}$; per $100,80 \mathrm{c}$; per $500, \$ 2.75$ : per $1,000, \$ 5.00$.

MICHEL (S) One of the very best of the extra early varieties. Medium (Extra Early) size berry, round-pointed. It is a bright red, colored evenly over the entire surface; flesh light crimson, juicy, sprightly acid quality. It is at its best when the berries are allowed to fully ripen on the vine. Splendid early berry for table use, and a shipper.

The plants are very rank, heavy growers and make so many runners that it is necessary to keep them thinned for best results. Thrives best on light, warm soils. If put on too heavy, rich land, all the strength is inclined 


\section{Standard Varieties}

Stratk City. Mo

to go to the plants, rather than to making berries. One of the best early varieties for cross-pollenation; very productive.

Per bunch of $25,25 c$; per $100,60 c$; per $500, \$ 2.00$; per $1,000, \$ 3.50$.

MISSIONARY (S)

(Mid-Season)

Missionary is the same type berry as the Klondike; beautiful, uniform, round shape, tapering slightly at the point; medium to very large size; deep scarlet color with dark red flesh. A berry that is very popular because of its firmness and ability to stand shipment, and recommended by the commission men for its handsome appearance in the package.

The plants are extremely hardy, vigorous, productive, good plant-makers, resembling Klondike, except that they are lighter green color. Berries retain their size throughout the season. It is preferred by many to Klondike and Lady Thompson, and promises to become one of the most popular berries of its season.

Per bunch of 25, 25c; per $100,60 c$; per 500, $\$ 2.00$; per 1,000, $\$ 3.50$.

MONROE (S) The Monroe is a very large, beautiful, dark red berry, smooth surface, a descendant of the Sample, and has many qualities of that variety. It is good quality, equaling Mar(Late) a splendid commercial berry, being a good shipper and a shall; firm flesh; a splendid commercial berry, being
good keeper, and also a very good berry for home use.

Plant stocky, vigorous, and makes a number of long runners. It ripens throughout a long season, the berries of the first few pickings being unusually large and productive.

Per bunch of 25, 35c; per $100,80 c$; per 500, $\$ 2.75$; per $1,000, \$ 5.00$.

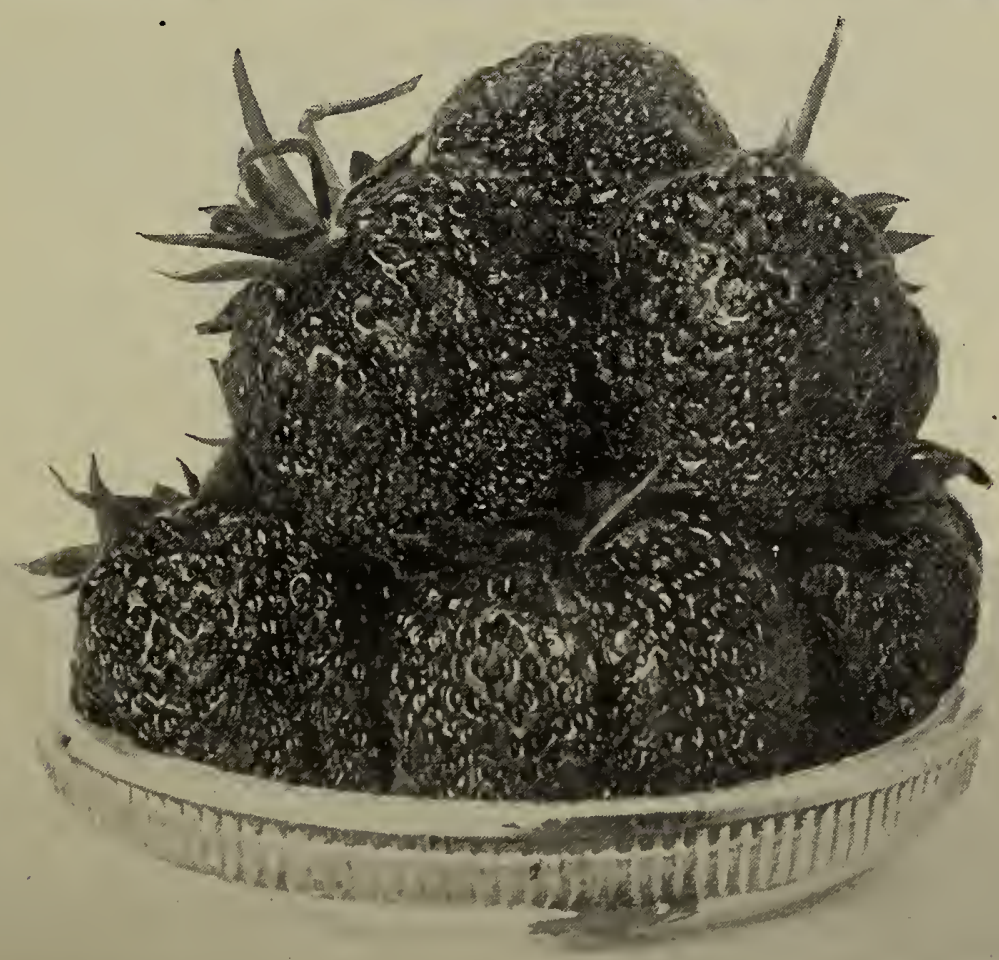

Ozark-One of the best of extra early berries. Very firm. Fine flavor. Great shipper. 


\section{Standard Varieties}

OZARK, EARLY (S)

(Extra Early)
The Ozark (or Early Ozark, as it is sometimes called) originated in this Ozark Mountain country, and is very popular because it is one of the few of the

extra early herries that has the good qualities of the later-ripening varieties. It has proved especially valuable in the Northern and Southern States. Roundish, oval shape, large average size, fully equaling the Gandy in this respect. Colors evenly, taking on an unusually dark rich red. The flesh is a deep crimson throughout and has a firm, meaty texture with rich subacid quality, almost sweet, very good. It is one of the firmest-fleshed berries grown, is one of the very best shippers among the early varieties.

The plant is ideal in many ways. Makes just enough runners to insure the best results in fruiting. The leaves are a dark green color, luxuriant, thick and leathery, very healthy and vigorous in appearance. It produces an abundance of pollen and is very productive; not easily killed by late frosts and freezes. Thrives best on fertile soil.

Per bunch of 25, 30c; per 100, 70c; per 500, \$2.25; per 1,000, \$4.00.

SAMPLE (P) Sample has the ideal Strawberry shape, resembling that of (Late) a top rounded at the point; one of the largest in size. Stem and calyx, which are small, remain green for days after the berries have been picked. Very dark red, attractive color, with prominent seeds, which turn red as the berries ripen; flesh bright red; ripens and colors evenly, very good quality. Its firm flesh and ability to stand shipment to distant markets make it a very popular berry and one that will compare favorably with the Aroma in size and color.

Plants are strong, thrifty, and make a number of runners, giving a good fruiting row; one of the most productive varieties grown, the berries ripening over a long period, and planted largely in the Northeastern section, and is the only pistillate variety that comes up to the high standard demanded of all late-ripening berries.

Per bunch of 25, 30c; per 100, 70c; per 500, $\$ 2.25 ;$ per $1,000, \$ 4.00$.

\section{SENATOR DUNLAP (S) (Mid-Season)}

Senator Dunlap is to the North and Eastern districts what the Aroma is to the Central States, and, with the exception of Son's Prolific, is the only berry that comes up to the standard of the Aroma for dependability and as a money-maker. It is a large handsome berry of the Warfield type, tapering to a point or wedge-shaped, very uniform in size and appearance. The deep glossy red color shades to a dark red or scarlet on the under side of the berry; prominent yellow seeds, forming a beautiful contrast; far above the average quality, exceedingly juicy and tender; delicate flavor, which makes it a popular variety with the consumer. Flesh is bright red, firm, and stands shipping and an unusual amount of rough handling; one of the best for preserving and canning, making a rich, red syrup, and the berry retains its bright red color.

The plant is one of the hardiest and most vigorous grown. Develops an unusually heavy crown; the foliage is tall, upright, bright green with long 


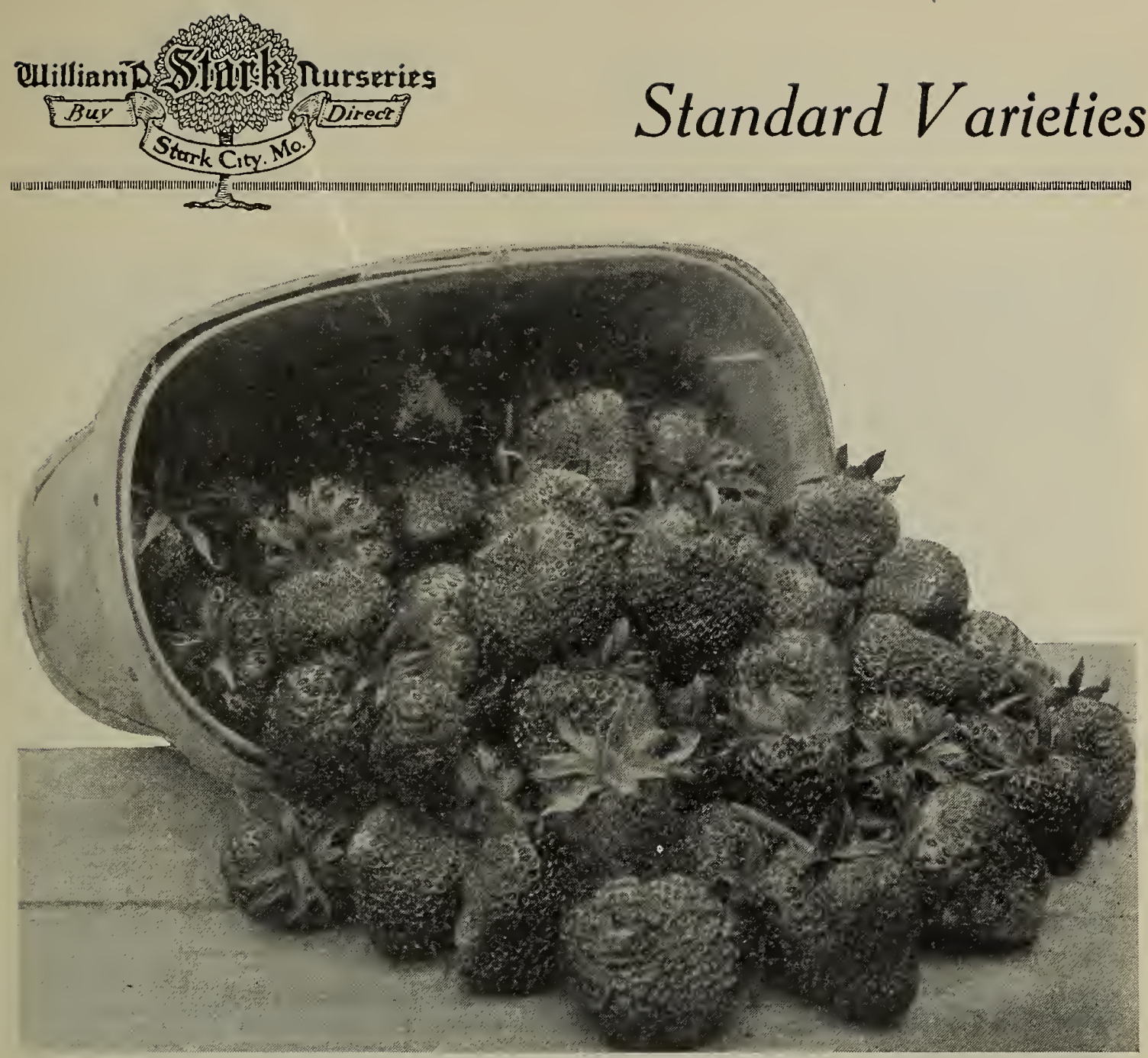

Sanator Dunlap-Large, handsome. One of the greatest of money-makers. Ripens early, long flowering season. Plant heavily of Senztor Dunlap for the utmost in results.

leaves. The Senator Dunlap is not only one of the hardiest, but adapts itself to all kinds of soil and climates, and thrives under any system of management. It is a good plant-maker, producing enormous runners and forming a splendid fruiting row. Because it is such a prolific plant-maker, they should be set 12 to 18 inches farther apart in the row than other varieties. It responds quickly to expert care, yet is one of the most productive varieties under unfavorable conditicns. Senator Dunlap is a "perfect" or staminate variety and produces an abundance of virile pollen. It is one of the most satisfactory varieties for planting with the pistillate or imperfect varieties and is universally used as a pollenizer for Warfield by commercial growers. It blooms at the same time. The fruit ripens about the same time and the berries are near enough alike in appearance for them to be packed together in the same crate if the grower wants to avoid the bother of keeping them separate.

"The plant is strong and healthy, a rampant runner, and takes good care of itself. The fruit is not quite the very largest, but of regular form, a bright glossy red, very firm, and a splendid keeper and shipper. It makes one of the best canning berries. It not only ripens early, but continues through the whole season."-The Orchard and Fruit Garden, by E. P. POWELL.

Per bunch of $25,25 c ;$ per $100,60 c$; per $500, \$ 2.00 ;$ per $1,000, \$ 3.50$. 


\section{Standard Varieties}
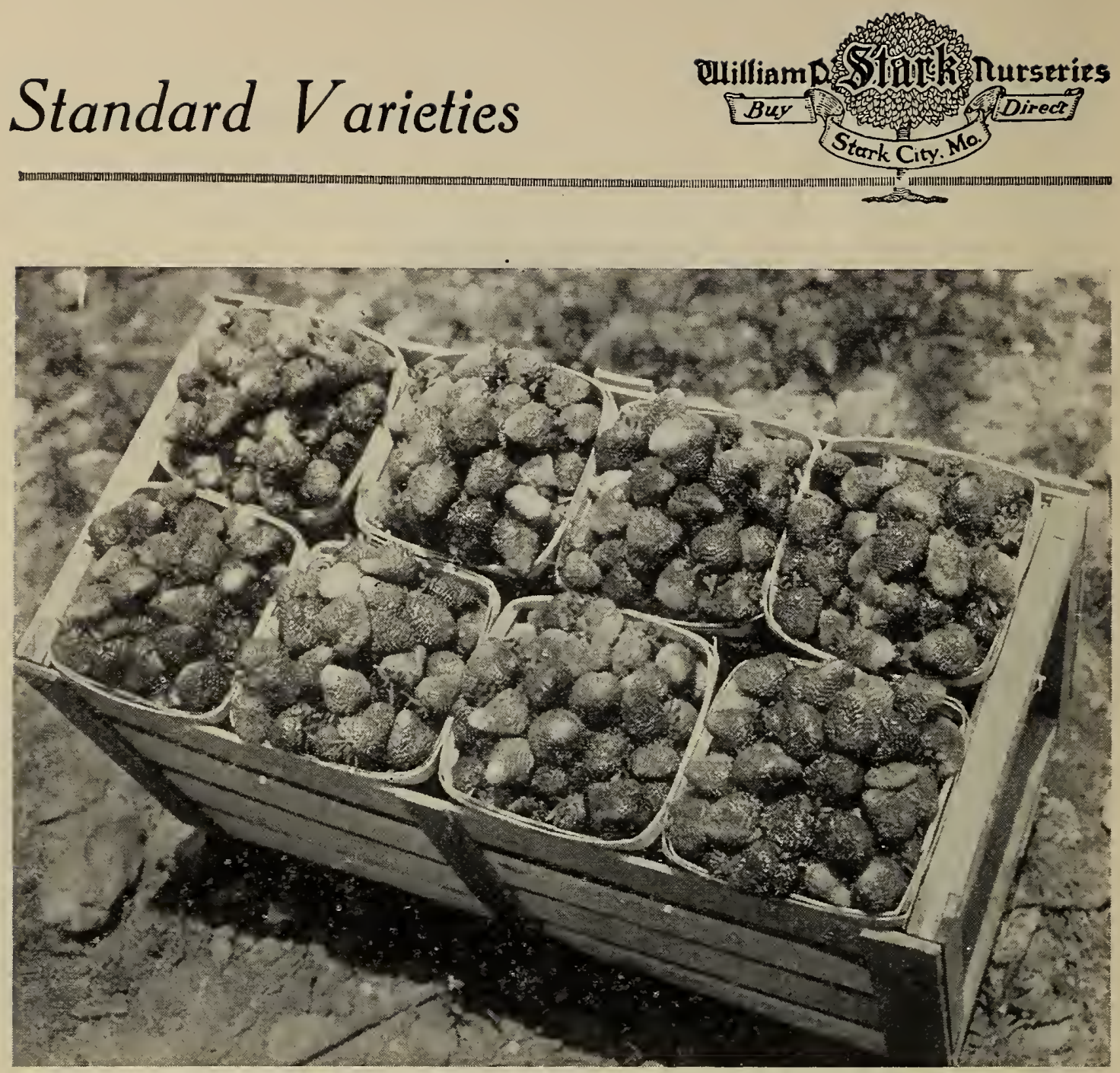

Son's Prolific-Combines the good qualities of Aroma and Bubach. It thrives on sandy land where Aroma does not succeed. Best shipper of all. A berry we particularly recommend to our customers who want an especially fine commercial berry.

SON'S PROLIFIC (S) Son's Prolific is a cross between the Aroma and (Late)

(Early in Canada)

Bubach, combining the good qualities of both. It is one of the three great varieties which combine the essential Strawberry qualities. Like the Aroma and Senator Dunlap, it has the attractive appearance, hardiness, productiveness, and ability to stand long-distance shipment that place these three varieties in a class by themselves. The berry is uniform, round shape, tapering slightly, being a little more pointed than the Aroma. They are larger in size than the Aroma, and of a darker, richer color. After years of fruiting and comparing it with the best varieties, it has proved to be the best color and the best shipping berry of them all. Berries ripen early, no green tips formed.

The foliage is rich, glossy, and heavy. It is a satisfactory plant-maker, forming a good hedge-row. The crown is heavy and the roots are very long and fibrous, going down into the ground, so that the plant is able to withstand drouth, and it will thrive on sandy land where the Aroma does not succeed. Son's Prolific commences to ripen same season as Aroma, but matures crop in a shorter period. The stem is stronger and heavier, and stands higher from the ground than either of its parents, the Aroma and Bubach.

For perfect plant growth, as to size, color, shape, flavor, firmness, and 


\section{Standard Varieties}

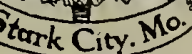

productiveness of the berries, Son's Prolific is best of all the late commercial varieties.

Per bunch of 25, 35c; per 100, $80 \mathrm{C}$; per 500, $\$ 2.75$ : per 1,000 , $\$ 5.00$.

TEXAS (S)

(Extra Early)

The Texas is a $\mathrm{m} \mathrm{e} \mathrm{d} \mathrm{i} \mathrm{u} \mathrm{m}$ to large size berry; uniform, roundish shape, tapering slightly toward the point. Dark, glossy crimson color; flesh is a light red, firm, meaty, rich, juicy; a distinctly tart flavor, and the berries are uniform in size and shape; every one is marketable, no culls. It is an excellent shipper, and its high color and uniform size give it a very pleasing appearance in the crate.

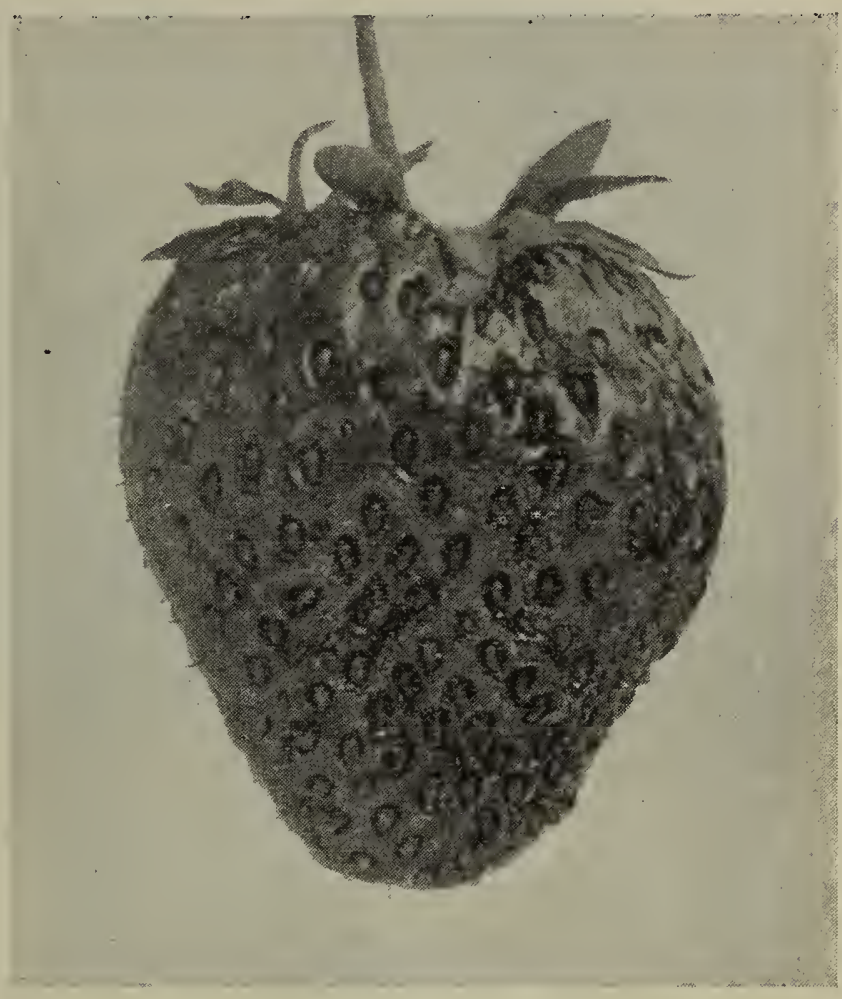

Texas-Splendid for either home or market. Very hardy and productive.

The plant is healthy, vigorous, and one of the freest from rust; makes a fair number of runners, forming a good fruiting row. It is hardy, and thrives in all soils and climates, producing a large number of blooms, and, if these are killed by frost, a second lot is frequently put out, giving a moderate crop the same season.

Plants come into bearing very young and are especially productive. While the Texas is an extra early berry, it has an unusually long fruiting season, giving a longer time in which to market the crop, and the picking overlaps that of the later varieties. The Texas is one of the best berries for the south half of the United States, and it is generally adaptable and should be as widely and universally planted in the North as the Haverland.

"One of the longest-season berries we have. A good variety for both commercial and home use."-Virginia Experiment Staiion, T. C. JoHnson.

Per bunch of 25, 30c; per 100, 70c; per 500, $\$ 2.25$; per 1,000, $\$ 4.00$.

WARFIELD (P) The Warfield is known from the Atlantic to the Pacific, from the Gulf to Hudson's Bay, and is a popular, standard variety everywhere. Medium to large size, beautiful, (Mid-Season) regular shape, tapering to a rounding point. Has a neat slender stem and green calyx, joined to the berry in such a way as to form a short neck. The Warfield is a very highly colored berry, dark glossy red, prominent yellow seeds; flesh is a deep red, which extends through to the center, and it retains it color after picking. It has a spicy, sub-acid flavor, tart enough to be a fine relish, moderately firm, keeps fairly well in storage.

The Warfield is an excellent table berry and especially desirable for 


\section{Standard Varieties}
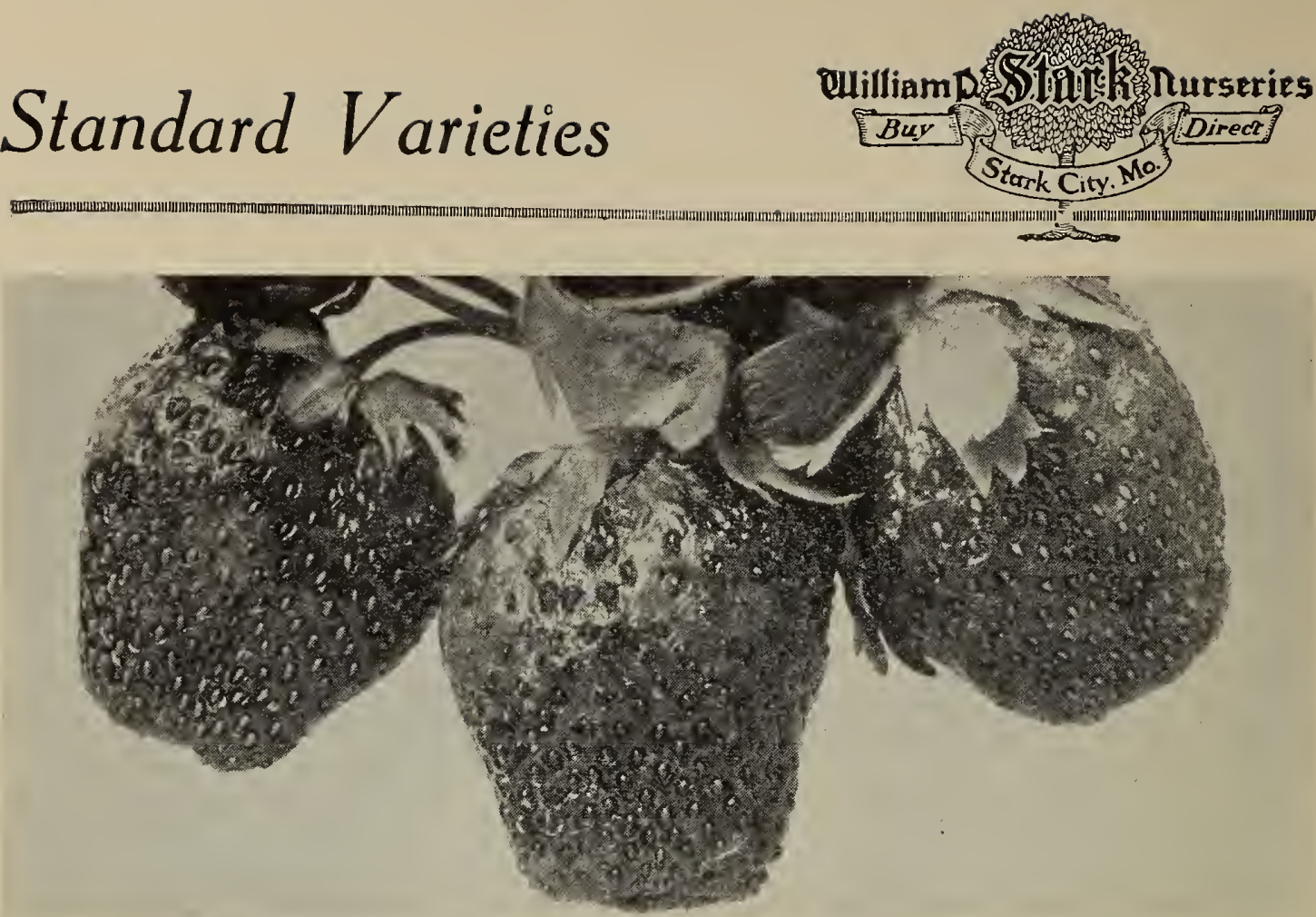

Warfield-Known everywhere. Enormously productive. Fine for shipping, home use or canning.

canning and preserving, because it holds its beautiful color after canning; has rich flavor and is one of the best for nearby markets. It is not only a great berry for local markets, but one of the best commercial varieties for long, distant shipments, when picked in a fine condition.

The Warfield is a persistent plant-maker, and the plants must be thinned out to get the best results. Foliage is good; should have a staminate (S) variety planted every other row in order to give thorough cross-pollenation. It is enormously productive, combining many excellent qualities, and is a splendid berry for the main crop. (See Senator Dunlap for best pollenizer.)

"Popular as market variety across the continent."-American Hiorticultural Manual, by Professors Budd And Hansen.

Per bunch of 25, 25c; per 100,60c; per 500, $\$ 2.00$; per 1,000, $\$ 3.50$.

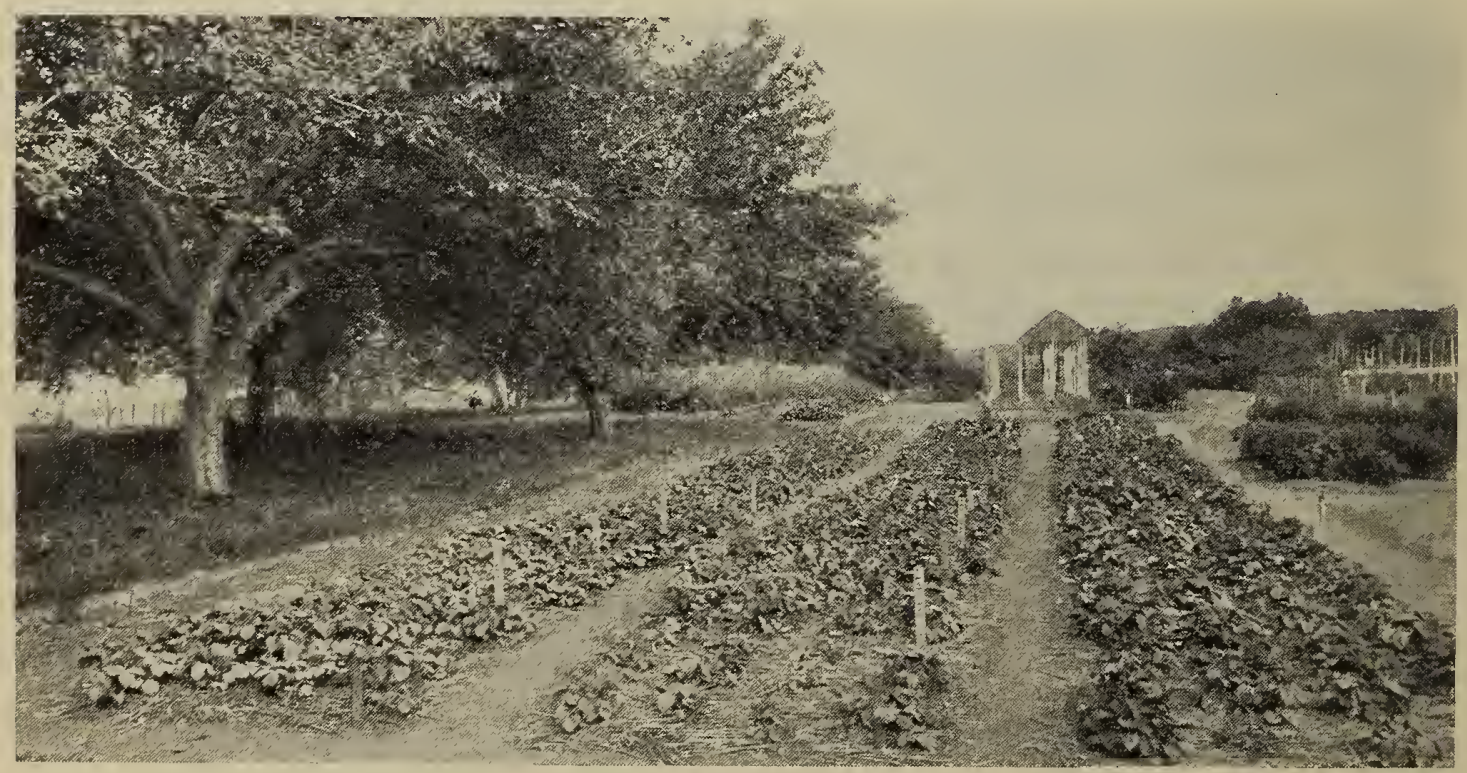

A small space in the home garden will give all the strawberries you ard your family can, eat, with enough left to sell at fancy prices. See Special Collections on opposite page. 


\section{Collections}

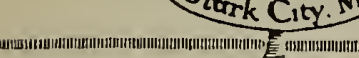

\section{Special Money-Saving Collections.}

Many fruit-growers who are not familiar with Strawberries have asked us to select varieties suited to their locality and their requirements. To meet this demand and to save you money on the purchase price, we are offering the special collections listed below. In these collections we put up named varieties of different seasons of ripening which are suited to your particular locality. (Whenever a pistillate $(\mathrm{P})$ variety is sent, the proper staminate (S) variety is also included for cross-pollenation.)

In the smaller collections we give varieties that are particularly adapted to the home garde'n. In the large acre collection we put up varieties that are noted money-makers. The plants in these collections are the best quality, the same in every respect as used on all of our orders. We select the varieties. You giet the best plants of the kind best suited for your locality. If you are not sure as to what is best; do not take any chances, but send in your order promptly, and we will reserve the plants as shown in the different collections and have them ready for early shipment.

\section{$\$ 2.00$ No. 1 Home Garden Collection.}

\section{Standard Plants.}

This is one of the most generally popular collections among those who want a low-priced Strawberry garden. It includes 100 plants each of an extra early, early, medium, and late variety. It will plant a row 800 feet long or a piece of ground 57 feet by 57 feet square with the plants set 2 feet apart in rows 4 feet apart. In the garden the rows are often set 3 feet apart, instead of 4 . When this is done, it will take a place 50 feet square. With varieties of from extra early to late, you will have a supply of delicious ripe strawberries for your family and your friends throughout the entire growing season, and for the winter's supply of preserves, jams, and canned berries at a cost of less than 1 cent a quart. No matter how small your ground, you can plant this collection and get results that willpay you many, many times over. This is an unusual offer in that you can get a ccmplete assortment in a small order at prices usually given only on large quantities.

\section{$\$ 3.00$ No. 2 Everbearing Home Garden Collection.}

\section{Standard Plants, 100 Everbearing Plants.}

This collection is like No. 1, except that we have added 100 of the famous Everbearing Strawberries in place of the extra early standard plants. Of the standard varieties there are 100 early, 100 medium, and 100 late plants, 100 Everbearing (50 plants each of the Americus and Progressive). These Everbearing plants ripen the first crop extra early in the season, thus taking. the place of the extra early variety in Collection No. 1 , but they continue to blosscm and bear fruit throughout the summer under favorable conditions. Even though there should be a drouth or you should neglect your garden through the summer so as to check the development of the fruit buds, it will reward you, nevertheless, with another full crop in the fall. Think of it, 


\section{Collections}

fresh ripe strawberries for the entire family as late as September and Octcber or November, until you have a hard killing frost! All the berries you want for your own use, and what you sell will pay for the sugar and expense of putting up the winter's supply of preserves and canned fruit.

\section{$\$ 5.00$ No. 3 Local Market Collection.}

\section{Everbearing Strawberries, E00 Standard Plants.}

This collection is made up especially to meet the demands of those who want to raise more berries than they need for home use. It has 200 plants each of the early, medium, and late standard varieties, then 100 each of the two best Everbearing varieties, Americus and Progressive. It will plant a row 1,600 feet long or a piece of ground 80 feet square with plants set every 2 feet in rows 4 feet apart, and it is especially suited for supplying a home market. This is the collection to plant if you live in town and have a back yard and want to make some extra spending money, or in the country and have a place in the garden that you can use. It will pay many times more than the same space put into vegetables and also furnish all the fresh ripe berries that you and your friends can use. You can get the highest prices for your berries because you are able to deliver the best to the purchaser in a fresh, ripe condition. Prepare your ground just as soon as possible and send in your order for early spring shipment.

"Four rows twenty rods long were planted, the rows being four feet apart, consequently there was just twenty square rods in the patch, or oneeighth of an acre (660 plants required). Those four rows produced 1,600 boxes of extra choice berries, which sold for $\$ 3.60$ per crate, or $15 \mathrm{c}$ a box, bringing me $\$ 240-$ a very good showing for an eighth of an acre." -E. E. CRAWFORD, Oklahoma.

\section{$\$ 15.00$ No. 4 One-Acre Market Collection}

\section{5,500 Standard Plants-Enough for One Acre.}

This collection is used by a great many market gardeners, as well as people living in the suburbs, who have several vacant lots and want them to pay a good profit. Many farm owners find it a very good investment, because one acre, properly handled, will often yield several hundred dollars net profit, which goes a long way toward paying expenses when there is an off year in other crops. Remember that the standard varieties of Strawberries are picked early in the spring; that there is seldom, if ever, a complete failure, and this acre of Strawberries not only provides a large net money crop, but affords the children in the neighborhood something to do in picking them. Of course this is an expense deducted from the profits, but if they happen to be your own children, they have that much extra money for spending. This collection is made of 1,500 early varieties, 2,000 medium, and 2,000 late standard varieties, and will plant one acre with the plants set every 2 feet in rows 4 feet apart. These varieties are suited to your locality, and we will send varieties that are good shippers and keepers so that you can ship them to the markets and allow the retail merchants plenty of time in which to sell them to their customers. The people are realizing more than ever the necessity of diversified farming. Remember the old saying: "Don't put all of your eggs in one basket."

Plant this acre collection for quick money returns. Order now and get the best results by planting early. 


\section{How to Plant}

\section{Planting Directions.}

What Strawberries are best suited to your soil, location and requirements? That is the first and one of the most important questions to decide. Must it be an early or late variety? An extra good shipper or a large fancy berry for market that will pay especially high prices" Different markets and different individuals. have different preferences. Some like a round, others a long berry; some a bright red, others a dark red strawberry. For commercial markets and long-distance shipment, the choice of kinds is narrowed down to a few for each locality; but where you are planting for nearby markets and home use, you have a wider range of varieties to choose from. See our complete description of each variety on pages 12 to 28. Also the tables giving the kinds recommended for each State and for different purposes on pages 38,39 and 40 .

Varieties marked "S" are "staminates" and have perfect blooms. Those marked "P" are "pistillates" and have imperfect blooms. Pistillate varieties sıould be planted near staminate varieties to get thorough cross-pollenation. Large fields of staminate varieties can be planted alone. Do not plant pistillate or imperfect-flowered varieties alone, but for every three or four rows of pistillate varieties planted there should be a row of a staminate variety alongside of them.

\section{When to Plant.}

Strawberry plants may be set either in the spring or fall. The Northern planters generally set theirs in the early spring; in the South they often set the plants in the fall.

Spring planting is generally the best. In early spring the plants are dormant and can be set at this time with little or no danger of drying out in handling, and they can be transplanted befiore they form the new roots for the season. In the autumn the plants store up a large supply of food in the crowns and become plump and stocky, and are able to live for a long time on this stored-up food. For this reason it is especially advisable to plant early in the spring, when the plants are stored full of food, and before they have started to make their growth. We can supply the plants when you want them, but the best time is the early spring. Send your order in as soon as possible and have your plants reserved.

\section{Receipt of Plants}

When the plants arrive at your station, get them at once. Unpack the box without delay. If you are not ready to plant, dig a shallow trench about five inches deep and "heel them in." One side of the trench should be smooth and slope at an angle of 45 degrees. Cut each bundle, shaking out the roots. Lay the plants side by side, with top of the crown just above the surface of the ground. Cover the roots with dirt. Then another row of plants can be set alongside the first, and so on. In this way a great mahy plants can be put in a small space.

\section{Preparing the Plants Before Setting Them Out.}

Just before the plants are set out, remove all of the foliage except the growing boint and one leaf. This leaf should be the smallest and last one produced by the plant. Cut back the roots about one-third. This can be done very rapidly with a sharp knife, The plants can be placed in a large bucket with a little water in the bottom. Where several men are planting, a boy usially drops the plants just ahead of the men. 


\section{How to Plant}

\section{Cultivalion.}

The cultivation of Strawberries is very simple. A regulation hoe with a cutting edge about 4 inches wide and an ordinary one-horse eleven-toothed cultivator which has a lever to regulate the depth of the teeth is bes't. The cultivation should always be shallow. In a small field a wheel-hoe or manpower cultivator, such as the Planet Jr., Iron Age, etc., is very satisfactory, and a great deal more can be done with them than an ordinary hand-hoe. In the first place, the cultivator should always be run in the same direction each time. The newest runners, which get out into "the middles," will be laid back by the teeth of the cultivator. The plants should be cultivated all summer, and if the matted-row system is followed, the new runner plants should be confined to a strip 12 to 15 inches wide. Some growers cover the tips of the runners with dirt when hoeing; however, this is not at all necessary if the ground is loose and mellow, as the plants will take root without any assistance. In cultivating and in hoeing out the rows, the following should be kept in mind-that the Strawberry is a shallowrooted plant; at the same time it is a plant that requires considerable moisture, so the centers of the rows should be cultivated as soon after each rain as the ground becomes dry enough to work and as often thereafter as possible, every ten days to two weeks. The cultivator teeth should be run shallow and a loose dust mulch about two inches deep should be kept in the center of the row. Cultivate so as to keep the ground level. Sometimes early in the season a hard crust forms after a beating rain, and in breaking this crust there are a great many clods turned up near the plants and the roots are more or less exposed. When this happens, run a wooden roller over the row of plants. It will not hurt the plants, and it will crush the clods and pack the dirt down tight about the plant's and bring the moisture to the surface again. Rolling is not necessary except during very dry weather, and when the dirt has been loosened too close to the plant. If you want the big yields of several hundred dollars an acre, keep on cultivating; do not stop simply because you have killed all the weeds. It pays just as much to cultivate after the weeds are all killed as it did before.

\section{Mulching Strawberry Beds.}

A mulch is a covering for the ground and is usually made by spreading leaves or straw over the Strawberry bed. (A dust mulch is made by keeping the surface of the ground thoroughly loosened and pulverized to a depth of several inches by cultivation-see under "Cultivation.") However, a mulch for Strawberry beds refers to a cover of some sort of coarse trash. A mulch of this kind helps to keep the soil cool and moist during the fruiting season. It keeps the berries free from the dirt which splatters up on them during a rain, and it affords winter protection and prevents plants on clay soil from being heaved out of the ground by the alternate freezing and thawing. In the North this mulch is generally applied in October or November for winter protection. In the South, where winter protection is not necessary, the mulch may be applied just before the fruiting season. In many sections of this Ozark country it is not necessary to mulch Strawberries, as the surface of the ground is almost completely covered with gravel or chips of flint rock that keep the fruit clean and form a natural mulch which holds the moisture in the soil.

The material used for making a mulch is that which is the easiest and cheapest for you to get, and will not pack too close to the plants, and which will keep the berries clean. It should be as free from weed seed as possible; timothy is especially bad in Strawberry beds. Straw, prairie grass or slough 


\section{How to Plant}

Stork City. Mo.

grass is used where they are available; coarse straw manure is sometimes used, but o f t e n contains too many weed seeds. Forest leaves that will not pack down tight are also used. Corn stalks that have been run through a shredder make a good mulch, also pine needles are used extensively in the Scuth. When none of these materials can be had cheaply, a good mulch can be grown by sowing a small patch of c orn, sorghum or Kaffir corn very thick on the ground so it will grow thick and have fine small stems. A small area properly cut and cured will make a mulch for a large Strawberry field. In the North and in the Northwest, where they have the drying winds, the mulch is applied about 4 inches thick, and in some places 6 inches thick. The mulch should not be so thick that plants can not grow through. Where the plants fail to come through, they will grow beneath the mulch and will be white and weak. Wherever the plants have trouble getting through, the mulch should be raked off that part of the row early in the spring.

\section{Setting the Plants}

Strawberries are sometimes set by plowing out a shallow furrow, but this is not generally recommended. The best. way is to have the ground prepared and leveled as described under "Preparation of Land," and then laid off in rows. The rows can be marked with the regulation corn-marker, or if the field is a small one, a string can be used as a guide and the mark made with

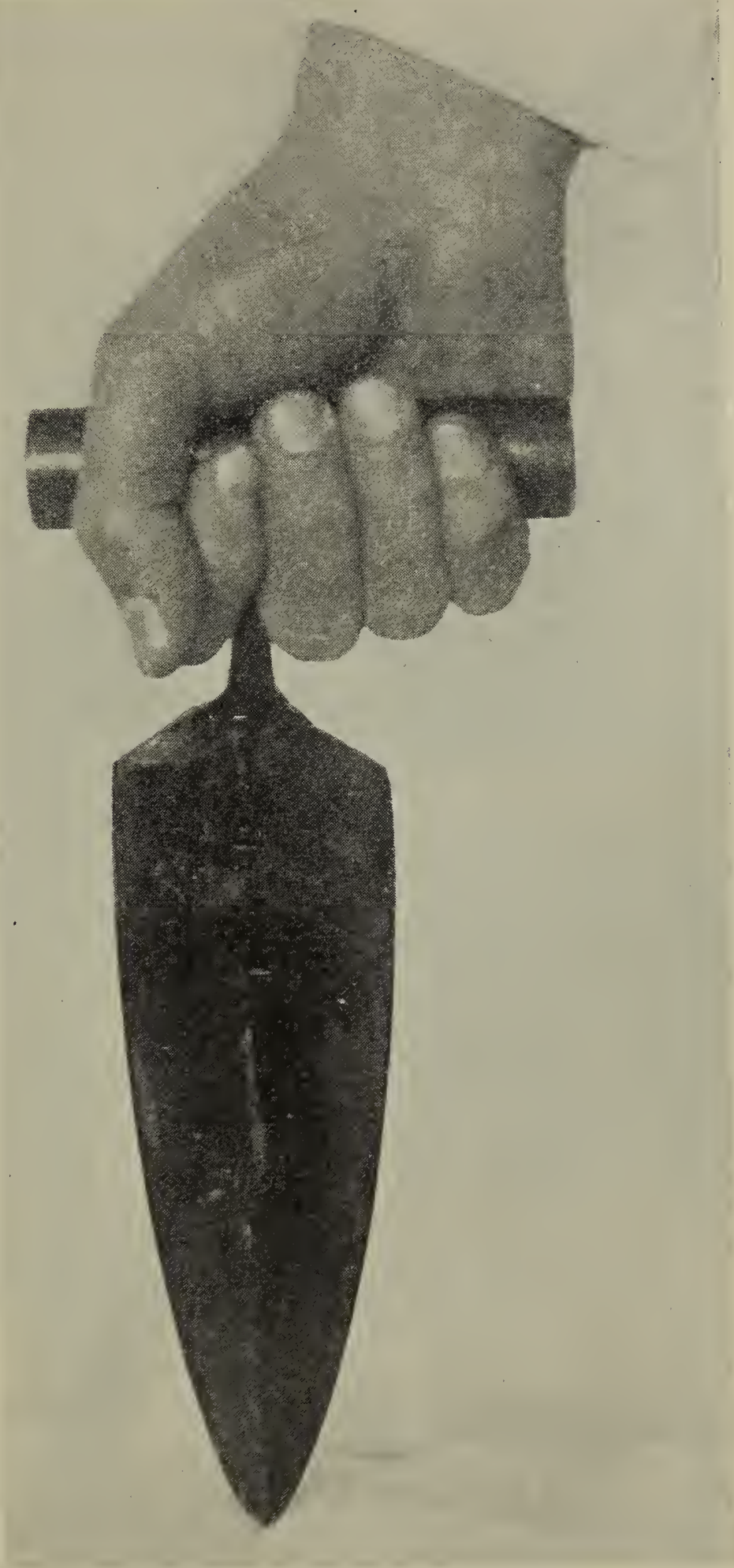

\section{Planting Dibble-Our Own Make}

A hand-forged all-steel tool, which we first made for our own use because we could not get a durable Dibble of just the right size and shape. Makes planting easier. Order one sent with your plants.

. 


\section{How to Plant}

the edge of a spade. Either a spade or a "dibble" can be used for setting the plants. Where there is a great deal of planting to do, a dibble is more satisfactory. It brings the man closer to his work. It is not so hard on his back and he can get more done in a day and do it better. Our special dibble which we make for this purpose is shown on page 33 ; however, very good work can be done with a spade. In using either tool, thrust it into the ground to a depth of 5 to 6 inches, and then work it sideways so as to open out a deep narrow cut in the ground. Set the strawberry plants in this opening, straightening the roots, spreading them out like a fan. The plant is placed in the ground while the tool is still in the opening. When the roots are in place, draw out the tool, which lets some of the dirt fall back; then set the tool to one side of the first cut, shoving it into the ground again and pressing it sideways over against the first hole in which you have put the plant. This closes the dirt about the roots and packs it. Setting the plant at just the required depth is very important. The beginner is liable to set the plants too deep, so the mud washes into the crown, causing the plant to rot. The careless man often sets them too shallow. Just the right method is described on page 37 . Be sure to have the dirt pressed in tight about the plant. There is no danger of getting it too tight. The beginner is almost sure to leave the ground too loose. After the man has set the plants as described above, the dirt should be further pressed down by placing one foot on each side of the plant and packing the dirt tight about the roots and lower part of the crown.

\section{Picking Blooms from Newly Set Plants.}

In the standard varieties it is not expected that they produce a crop the first season they are set out. They are cultivated so as to make them form a large number of new runner plants, and the size of your crop the next season depends upon the number and vigor of these new runner plants. For that reason it is essential that all blooms and flower buds should be picked from the mother plants the first season they are set out, so all their strength will be given to the formation of new runner plants.

The bloom should be picked from Everbearing varieties the first part of the season if you want them to form a number of runners. The midsummer bloom can be left and a crop matured the latter part of the same season in which they were planted.

\section{Methods of Training.}

There are three methods of training Strawberries. They are (1) the matted row, (2) the single or double hedge-row, and (3) the hill system.

\section{Matted Row.}

This is the most generally used system throughout the entire United States in commercial beds and in home gardens, and it is especially popular where large acreages are planted to Strawberries and where labor is scarce. The expenses are less per acre. The rows are generally 4 feet apart with the plants 2 feet apart in the row, which takes 5,445 plants to the acre. Prolific plant-makers like the Senator Dunlap should be set 12 to 18 inches farther apart, and moderate plant-makers should be set 6 to 12 inches closer. The blooms are pinched off and the mother-plants are allowed to make os many new runners as they will form. The cultivators are always run in the same direction, so the runners, as they push out in the middle of the row, are turned back into the row by the cultivator teeth and all the new plants are made to grow in a strip 12 to 15 inches wide. Some growers set the rows 3 to $3 \frac{1}{2}$ feet apart, but the greater distance makes it easier to keep the middles open to cultivate and keep the weeds down. 


\section{How to Plant}

\section{Single Hedge-Row System}

This method is adapted to commercial planting on an intensive scale and is used by truck gardeners where the land is very valuable. The rows are 2 to 3 feet apart, plants being set 20 to 30 inches apart in the row. Each plant is allowed to produce two runners. The other runners are pinched off as fast as they are formed. These two new runners are trained to grow in the row in line with the mother-plant, one on either side. In this way each plant is 6 inches to a foot distant from its neighbor in the row. Large, strong plants are grown, and the berries are somewhat larger and of better quality. The surplus runners must be cut and strict attention must be given to this during the growing season, which makes the system rather expensive.

\section{The Double Hedge-Row}

The double hedge-row is the same principle as the single hedge-row, except the mother plant is allowed to form either 4 or 6 runner plants, instead of 2. These new runner plants are trained to form three parallel lines, one being the line of the mother plant, which is the same as in the single hedgerow, and then one row of new plants on each side of the original row. The two new lines are 7 to 9 inches distant from the original row in the middle. This has the advantage of a larger number of plants and berries than the single hedge-row system. Plants are usually set in rows 30 inches to 3 feet apart. About one-half of the ground is given to the three parallel lines. There is an open space of about $1 \frac{1}{2}$ feet between each double hedge-row, which can be cultivated with a horse cultivator.

\section{Hill System}

In the hill system the ground is usually laid off in regular beds. The beds are 4 feet wide with a path between them about 1 foot $91 / 3$ inches wide. The beds may be of any length desired. The plants are set 1 foot apart each way in the bed. This allows five rows of plants to each bed. This system requires about 33,795 plants to the acre, or 1,940 plants for a space 25 feet wide by 100 feet long, and as a method of intensive cultivation it has given some wonderful results. It requires heavy manuring, fertilizing and cultivation. No runners are allowed to form, the runners being pinched off as soon as they appear. 'This gives very strong heavy plants, and new plants grow up beside the mother plant, forming a heavy crown or stool which is enormously productive, bearing large loads of fruit. It requires a great amount of labor, and except for the home garden and special markets near the city it is not to be recommended.

\section{Number of Plants Required to Se! One Acre.}

1 foot $\times 1$ foot. ..........43,560

1 foot $x 1$ foot 6 inches.....29,040

1 foot $\times 2$ feet. . . . . . . . . 21,780

1 foot $\times 3$ feet. . . . . . . . 14,520

1 foot $x 4$ feet............ 10,890

2 feet $\times 2$ feet. . . . . . . 10,890
2 feet $x 2$ feet 6 inches. . . . . . 8,712

2 feet $x 3$ feet. ............ 7,260

2 feet $\times 3$ feet 6 inches........6,223

2 feet $\times 4$ feet. . . . . . . . . 5,445

3 feet $\times 3$ feet. . . . . . . . . . . 4,840

3 feet $\times 4$ feet. ........... 3,630

To determine the number of plants per acre for any given distance, multiply the distance between the plants in the row by the distance the rows are apart. Take the resulting answer and divide 43,560 by it. The resulting figures will give you the number of plants per acre.

For example:- To determine the number of plants, planted 2 feet $\times 4$ feet, required to set one acre: $2 \times 4=8 ; 43,560 \div 8=5,445$.

\section{Location}

Location, providing there is good drainage, is not as important for Strawberries as it is for some other fruits. A south slope will give berries a little earlier in the season, and sometimes they are better colored and a better 


\section{How to Plant}

flavor. The northern slopes do not ripen as soon, but the crops hold on longer and are not affected quite as much during drouthy seasons.

Good drainage comes first, and the land in the low frosty places should be avoided. The culd air settles down in the low places, and it is here they are more apt to be injured from spring frosts. On the other hand, land on small islands near rivers and lakes and along the shores of large bodies of water is less apt to be affected by frost, as the water holds a great deal of warmth and prevents frost injury on nearby lands. For the small home planting and the garden, the only thing to remember is not to plant on land that is wet and soggy for any length of time.

\section{Soil.}

Strawberries will thrive in a great many soils and locations. No other plants can be grown with profit in as many different parts of the country as Strawberries. The ideal Strawberry soil is a good loam, rich in humus and well drained. It is generally recommended that any soil that is good for corn or potatoes is good for Strawberries, but there are a great many exceptions to this. There are thousands of acres of profitable Strawberries grown on sandy soils that are too poor for good farming land, and others on rocky hillsides that are too thin for farm crops. In this Ozark country the rockiest land is often the most productive, and the flint rocks are so thick on the ground that they form a very satisfactory natural mulch. New land gives best results because of the several inches of leaf-mould plowed under after it is cleared of timber. Thriving as it does in almost all kinds of soils, it is impossible to recommend any one kind of soil that will give the best results, and it is literally true that all soils are good for Strawberries. The one requirement that is necessary in every case is that it be well drained.

\section{Preparation of Land}

The land should be put in a good mellow condition, and such tools as you use in your regular farm work can be used for this. The land should be fertile and able to hold moisture without being water-logged. It should be "mellow," so that it can be kept in good condition at all times. The preparation that favors any of the above requirements is always helpful. The land should be plowed deep in the fall or early spring.

As a rule, it is advisable to plow damp or clay soil or sod land in the fall. Otherwise spring plowing is generally favored, where it is possible to do it early in the season. In the spring it should be harrowed and disked until it is settled as deep as it was plowed. It is particularly important on springplowed land to have the ground well settled before the plants are set.

A good method of plowing is to turn a furrow at least 14 inches wide. Do not turn the soil clear over, but have one edge of the furrow lapped on the edge of its neighbor. The ground should be plowed 7 inches or more if the top soil is that thick. Never plow up more than a half-inch to an inch of the sub-soil at once. Sod land should be planted to a cultivated crop, such as corn or potatoes, for one year, to rid it of a white grub which feeds on the roots of the Strawberry plants. Many growers prefer to manure heavily in the fall, and plow the manure under; others manure in the pring after the ground is plowed, disking it in and pulverizing the ground.

In the spring before planting, the ground should be thoroughly chopped up with a disk and harrowed with a spike-tooth harrow. Work the soil until it is pulverized and put in a level condition. It is generally advisable to follow the harrow with a roller to pack down the earth. Usually a wooden roller is heavy enough for this work, except on very sandy soils. On clay soils a roller is inclined to pack the soil too tight, in which case a plank drag is better.

The one thing to remember is that on land that you have plowed or disked deeply it is necessary to have it well packed before the plants are set. 


\section{Proper Depth}
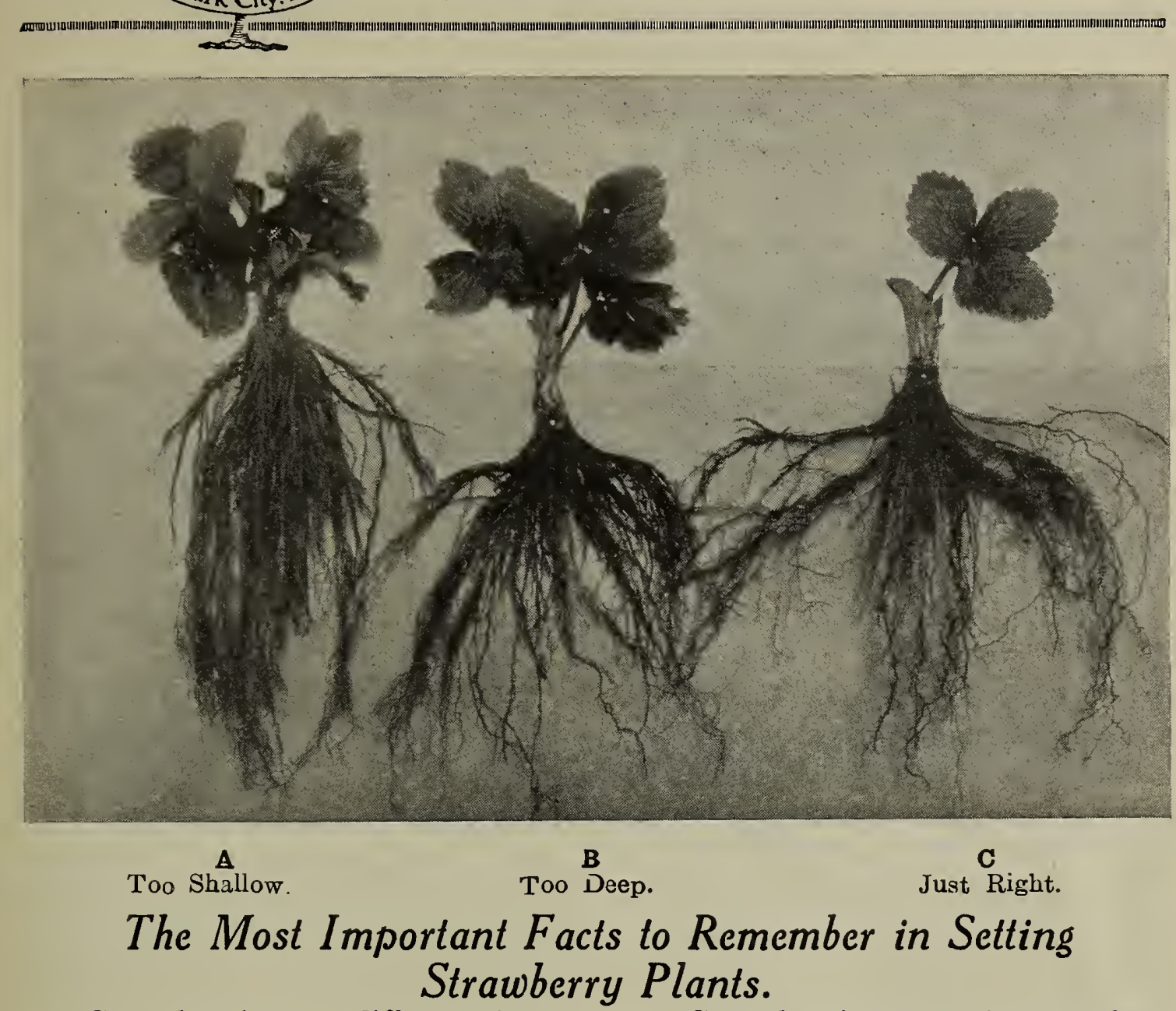

Strawberries are different from trees. Strawberries are soft, succulent, shallow-rooted plants, while trees have hard wood and deep roots. Remember this when you are setting out your Strawberry plants, and you will have no trouble in getting a very satisfactory growth.

A-This shows a plant that has been set too shallow. The crown is exposed. The air will get to this crown and dry it out and the plant will die. The lower part of the crown must always have moist dirt packed firmly about it.

B-This shows a plant that has been set too deep. The dirt will wash into the top of the crown and the new tender green leaves at the center will rot and the plant will die.

C--This shows a plant that has been set at the proper depth. The lower part of the crown is bedded firmly in the well-packed earth, while the upper part of the crown is free and open, so the new leaves, as they put out, will not have to push through the dirt. Notice the way the roots are spread out evenly. The roots should not be crowded together, and they should be straight, instead of being turned back or twisted; also notice that all of the leaves have been removed except one. Always have the lower half of the crown set firmly in the dirt and have the dirt packed tight about it. In cultivation never loosen the dirt immediately around the crowns of your Strawberry plants. The roots, where they join the crown, are always near the surface of the ground and should never be exposed. If you have very much planting to do, use our special planting dibble, shown on page 33 . 


\section{Selecting Varieties}

\section{Varieties for Your State.}

The question of which varieties of Strawberries to plant is often a perplexing one. We particularly want to emphasize the fact that Strawberries have a wider range of adaptability both as to soil and climate than any other fruit. Practically every variety in our list will thrive in every part of the country. There is no such thing as a "one best variety," and the answer to your question depends upon the purpose for which you want them-whether early or late, for home use or nearby markets or distant shipment, as an extra fancy berry for a market that will pay high prices or a berry that must stand shipment. From this you will see that the requirements are so different that you must plant different varieties for different purposes.

The following list gives varieties that have been thoroughly tested and proved in each State. However, varieties are constantly changing. Some good ones are being succeeded by those that are better, new sorts are constantly coming into prominence, and because one of the newer kinds is not listed below in your State does not mean that it may not be an exceptionally good one for you to plant. The fact that it is not listed means it has not been widely fruited and recommended by the leading growers in your State. Read the detailed variety descriptions, pages 12 to 28 , which give the characteristics of the berry and plant, and if there is one which fulfils your requirements, certainly give it a thorough trial, even though it is not mentioned under your State in the list below.

Alabama.-Aroma, Brandywine, Bubach, Crescent, Gandy, Klondike, Lady Thompson, Michel, Missionary, Ozark, Senator Dunlap, Son's Prolific, Texas.

Everbearing.-Americus, Progressive.

Arizona. - Aroma, Bubach, Crescent, Haverland, Klondike, Lady Thompson, Missionary, Ozark, Sample, Son's Prolific, Senator Dunlap, Texas.

Everbearing.-Americus, Progressive.

Arkansas.-Aroma, Brandywine, Bubach, Crescent, Evening Star, Gandy, Glen Mary, Haverland, Klondike, Lady Thompson, Michel, Missionary, Ozark, Sample, Senator Dunlap, Son's Prolific, Texas, Warfield.

Everbearing.-Americus, Progressive.

California.-Aroma, Bubach, Brandywine, Evening Star, Gandy, Helen Davis, Klondike, Lady Thompson, Marshall, Missionary, Senator Dunlap, Son's Prolific, Texas.

Everbearing.-Americus, Progressive.

Colorado.-Aroma, Brandywine, Bubach, Crescent, Evening Star, Gandy, Haverland, Marshall, Ozark, Senator Dunlap, Son's Prolific, Texas, Warfield.

Everbearing.-Americus, Progressive.

Connecticut.-Aroma, Brandywine, Bubach, Crescent, Gandy, Haverland, Mar-
shall,4Michel, Ozark, Senator Dunlap, Son's Prolific, Texas, Warfield.

EverbeariNg.-Americus, Progressive.

Delaware.-Aroma, Bubach, Evening Star,, Gandy, Haverland, Michel, Ozark, Sample, Senator Dunlap, Son's Prolific, Texas.

Everbearing.-Americus, Progressive.

Florida.-Aroma, Brandywine, Bubach, Klondike, Lady Thompson, Michel, Missionary, Ozark, Senator Dunlap, Son's Prolific, Texas.

Everbearing.-Americus, Progressive.

Georgia.-Aroma, Brandywine, Bubach, Crescent, Gandy, Klondike, Lady Thompson, Marshall, Michel, Missionary, Ozark, Senator Dunlap, Son's Prolific, Texas, Warfield.

Everbearing.-Americus, Progressive.

Idaho.-Aroma, Brandywine, Bubach, Crescent, Gandy, Glen Mary, Haverland, Marshall, Ozark, Senator Dunlap, Son's Prolific, Texas.

Everbearing.-Americus, Progressive.

Illinois.-Aroma, Brandywine, Bubach, Crescent, Evening Star, Gandy, Haverland, Klondike, Lady Thompson, Michel, Missionary, Ozark, Sample, Senator Dunlap, Son's Prolific, Texas, Warfield.

Everbearing.-Americus, Progressive. 


\section{Selecting Varieties}

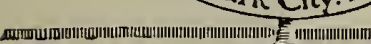

Indianz.-Aroma, ${ }^{\top}$ Brandywine, ${ }^{\nabla}$ Bubach, Crescent, Gandy, Haverland, Lady Thompson, Michel, Missionary, Ozark, Sample, Senator Dunlap, Son's Prolific, Texas, Warfield.

Everbearina.-A mericus, Progressive.

Iowa. - Aroma, Brandywine, Bubach, Crescent, Gandy, Haverland, Michel, Ozark, Senator Dunlap, Son's Prolific, Texas, Warfield.

Everbearing.-Americus, Progressive.

Kansas.-Aroma, Brandywine, Bubach, Crescent, Gandy, Haverland, Michel, Ozark, Senator Dinnlap, Son's Prolific, Texas, Warfield.

Everbearing.-Americus, Progressive.

Kentucky. - Aroma, Brandywine, Bubach, Crescent, Gandy, Haverland, Lady Thompson, Michel, Missionary, Ozark, Sample, Senator Dunlap, Son's Prolific, Texas, Warfield.

Everbearing.-A mericus, Progressive.

Louisiana.-Aromaa, Brandywine, Bubach, Crescent, Gandy, Klondike, L a d y Thompson, Michel, Missionary, Ozark, Senator Dunlap, Son's Prolific, Texas.

Everbearing.-A mericus, Progressive.

Maine.--Aroma, Brandywine, B u b a c h, Crescent, Glen Mary, Haverland, Ozark, Sample, Senator Dunlap, Son's Prolific, Texas, Warfield.

Everbearing.--Americus, Progressive.

Maryland.-Aroma, Brandywine, Bubach, Crescent, Gandy, Glen Mary, Haverland, Lady Thompson. Ozark, Sample, Senator Dunlap, Son's Prolific, Texas, Warfield.

Everbearing.-Americus, Progressive.

Massachusetts. - Aroma, Brandywine, Bubach, Crescent, Gandy, Haverland, Marshall, Michel, Ozark, Sample, Senator Dunlap. Son's Prolific, Texas, Warfield.

Everbearing.-Americus, Progressive.

Michigan. - Aroma, Brandywine, Bubach, Charles I., Crescent, Gandy, Haverland, Marshall, Michel, Ozark, Senator Dunlap, Son's Prolific, Texas, Warfield.

Everbearing.--Americus, Progressive.

Minnesota. - Aroma, Brandywine, Bubach, Crescent, Haverland, Helen Davis, Klondike, Sample, Senator Dunlap, Son's Prolific, Texas, Warfield.

Everbearing.-Americus, Progressive.

Mississippi.-Aroma, Brandywire, Bubach, Crescent, Gandy, Klondike, L a d y Thompson, Michel, Missionary, Ozark, Senator Dunlap, Son's Prolific, Texas.

Everbanting.-Americus, Progressive.

Missouri. - Aroma, Brandywine, Bubach, Charles I., Crescent, Gandy, Haverland, Lady Thompson, Michel, Ozark, Sample, Senator Dunlap, Son's Prolific, Texas, Warfield.

Everbearing.-Americus, Progressive.
Montana.-Aroma, Brandywine, Bubach, Crescent, Gandy, Haverland, Michel, Ozark, Senator Dunlap, Son's Prolific, Texas, Warfield.

Everbearing.-Americus, Progressive.

Nebraska.-A roma, Brandywine, Bubach, Crescent, Gandy, Haverland, Michel, Ozark, Senator Dunlap, Son's Prolific, Texas, Warfield.

Everbearing.--Americus, Progressive.

Nevada.-Aroma, Brandywine. Bubach, Crescent, Gandy, Glen Mary, Haverland, Marshall, Ozark, . Senator Dunlap, Son's Prolific, Sample, Texas.

Everbearing.-Americus, Progressive.

New Hampshire.-Aroma, Brandywine, Bubach, Crescent, Gandv, Haverland, Michel, Ozark, Sample, Senator Dunlap, Son's Prolific, Texas, Warfield.

Everbearing.-Americus, Progressive.

New Jersey.-Aroma, Brandywine, Crescent, Gandy, Glen Mary, Haverland, Lady Thomoson. Ozark, Sample, Senator Dunlap, Son's Prolific, Texas, Warfield

Everbearing.-Americus, Progressive.

New Mexico.-Aroma, Brandywine, Bubach, Crescent, Fvening Star, Gandy, Haverland, Klondike, I,adv Thompson, Ozark, Sample, Senator Dunlap, Son's Prolific, Texas.

Everbearing.-Americus, Progressive.

New York. - Aroma, Brandywine, Bubach, Cardinal, Chesapeake, Crescent, Gandy, Haverland, Marshall, Michel, Missionary, Ozark, Senator Dunlap, Son's Prolific, Texas, Warfield.

Everbearing.-Americus, Progressive.

North Carolina.-Aroma, Brandywine, Bubach, Crescent, Gandv, Haverland, Klondike, Lady Thompson, Michel, Ozark, Sample, Senator Dunlap, Son's Prolific, Texas, Warfield.

Everbearing.-Americus, Progressive.

North Dakota.-Aroma, Brandvwine, Bubach, Crescent, Gandv, Haverland, Ozark, Senator Dunlap, Son's Prolific, Warfield.

Everbearing.-Americus, Progressive.

Ohio. - Aroma, Brandywine, B u h a c h, Crescent. Gandy, Haverland. Lady Thomp. son, Michel, Ozark, Sample, Senator Dunlap, Son's Prolific, Texas, Warfield.

Everbearing.-Americus, Progressive.

Oklahoma.-Aroma, Brandvwine, Bubach, Crescent, Gandy, Haverland, Klondike, Lady Thompson, Michel, Missionary, Ozark, Sample, Senator Dunlap, Son's Prolific, Texas, Warfield.

Everbearing.-Progressive, Americus.

Oregon.-Aroma, Brandywine, Marshall, Son's Prolific.

Everbearina.-Americus, Progressive. 
Pennsylvania. - Aroma, Brandywine, Bubach, Crescent, Gandy, Glen Mary, Haverland, Lady Thompson, Michel, Missionary, Ozark, Sample, Senator Dunlap, Son's Pro lific, Texas, Warfield.

Everbearing.-Americus, Progressive.

Rhode Island.-Aroma, Brandywine, Bubach, Crescent, Gandy, Haverland, Marshall, Michel, Missionary, Ozark, Senator Dunlap, Son's Prolific, Texas, Warfield.

Everbearing.-Americus, Progressive.

South Carolina.-Aroma, Brandywine, Bubach, Crescent, Gandy, Haverland, Klondike, Lady Thompson, Michel, Ozark, Sample, Senator Dunlap, Son's Prolific, Texas, Warfield.

Everbearing.-Americus, Progressive.

South Dakota. - Aroma, Brandywine, Bubach, Crescent, Glen Mary, Lady Thompson, Ozark, Sample, Senator Dunlap, Son's Prolific, Texas, Warfield.

Everbearing.-Americus, Progressive.

Tennessee.-Aroma, Brandywine, $\mathrm{Bu}$ bach, Crescent, Gandy, Haverland, Klondike, Lady Thompson, Michel, Ozark, Sample, Senator Dunlap, Son's Prolific, Texas, Warfield.

Everbearing.-Americus, Progressive.

Texas. - Aroma, Brandvwine, Bubach, Crescent, Gandy, Klondike, Lady Thompson, Michel, Missionary, Ozark, Son's Prolific, Texas, Warfield.

Everbearing.-Americus, Progressive.

Utah. - Aroma, Brandywine, B u b a c h,
Crescent, Gandy, Glen Mary, Haverland, Marshall, Ozark, Senator Dunlap, Son's Prolific, Texas.

Everbearing.-Americus, Progressive.

Vermont.-Aroma, Brandywine, Crescent, Gandy, Glen Mary, Haverland, Marshall, Michel, Ozark, Sample, Senator Dunlap, Son's Prolific, Texas, Warfield.

Everbearing.-Americus, Progressive.

Virginia.-Aroma, Brandywine, Bubach, Crescent, Gandy, Haverland, Klondike, Iady Thompson, Michel, Ozark, Sample, Senator Dunlap, Son's Prolific, Tezas.

Everbearing.-Americus, Progressive.

Washington.-Aroma, Brandywine, $\mathrm{Bu}-$ bach, Crescent, Gandy, Glen Mary, Haverland, Lady Thompson, Michel, Ozark, Sample, Senator Dunlap, Son's Prolific, Texas.

Everbearing.-Americus, Progressive.

West Virginia. - Aroma, Brandywine, Bubach, Crescent, Gandy, Glen Mary, Haverland, Klondike, Lady Thompson, Michel, Ozark, Sample, Senator Dunlap, Son's Prolific, Texas, Warfield.

Everbearing.-Americus, Progressive.

Wisconsin.-Aroma, Brandywine, Crescent, Gandy, Glen Mary, Haverland, Ozark, Sample, Senator Dunlap, Son's Prolific, Texas, Warfield.

Everbearing.-Americus, Progressive.

Wyoming. - Aroma, Brandywine, Bubach, Crescent, Gandy, Haverland, Ozark, Senator Dunlap, Son's Prolific, Texas.

Everbearing.-Americus, Progressive.

\section{Strawberries for Different Uses and Soils.}

Strawberries not only have a wide range of adaptability to different soils, but for different purposes and uses as well; however, it has been found that some varieties are especially good under certain conditions.

We give a list showing these varieties below.

Commercial Market Berries.

Aroma, Bubach, Evening Star, Gandy, Haverland. Klondike, L a d y Thompson, Senator Dunlap, Son's Prolific, Sample, Texas, Warfield.

\section{Berries for Sandy Soils.}

Aroma, Brandywine, Climax, Crescent, Evening Star, Gandy, Haverland, Klondike, Lady Thompson, Michel, Missionary, Son's Prolific, Senator Dunlap.

\section{Berries for Heavy Clay Soils.}

Aroma, Americus, Bubach, Evening Star, Gandy, Haverland, Ozark, Sample, Senator Dunlap, Son's Prolific, Texas.

\section{Berries for Loamy Soils.}

Aroma, Bubach, Cardinal, Chesapeake, Crescent, Haverland, Helen Davis, Ozark, Progressive, Sample, Senator Dunlap, Son's Prolific, Texas, Warfield.

\section{Extra Large Berries.}

Aroma, Brandy wine, Bubach, Chesapeake, Evening Star, Gandy, Glen Mary, Haverland, Helen Davis. Marshall, Son's Prolific.

\section{Extra Quality Berries.}

Aroma, Brandywine, Bubach, Cardinal, Chesapeake, Crescent, Fendall, Gandy, Glen Mary, Haverland, Helen Davis, Klondike, Marshall, Michel, Sample, Senator Dunlap, Son's Prolific, Texas, Warfield.

\section{General Family Supply Berries.}

Americus, Aroma, Brandywine, Cardinal, Crescent, Gandy, Glen Mary, Haverland, Klondike, Marshall, Michel, Progressive, Sample, Senator Dunlap, Son's Prolific, Texas, Warfield.

Drouth-Resistant Berries.

Aroma, Brandywine, Chesapeake, Crescent, Evening Star, Gandy, Glen Mary, L a d y Thompson, Missionary, Ozark, Sample, Senator Dunlap, Son's Prolific, Texas.

\section{Canning Berries.}

Aroma, Brandywine, Klondike, Marshall, Senator Dunlap, Son's Prolific, Texas, Warfield. 

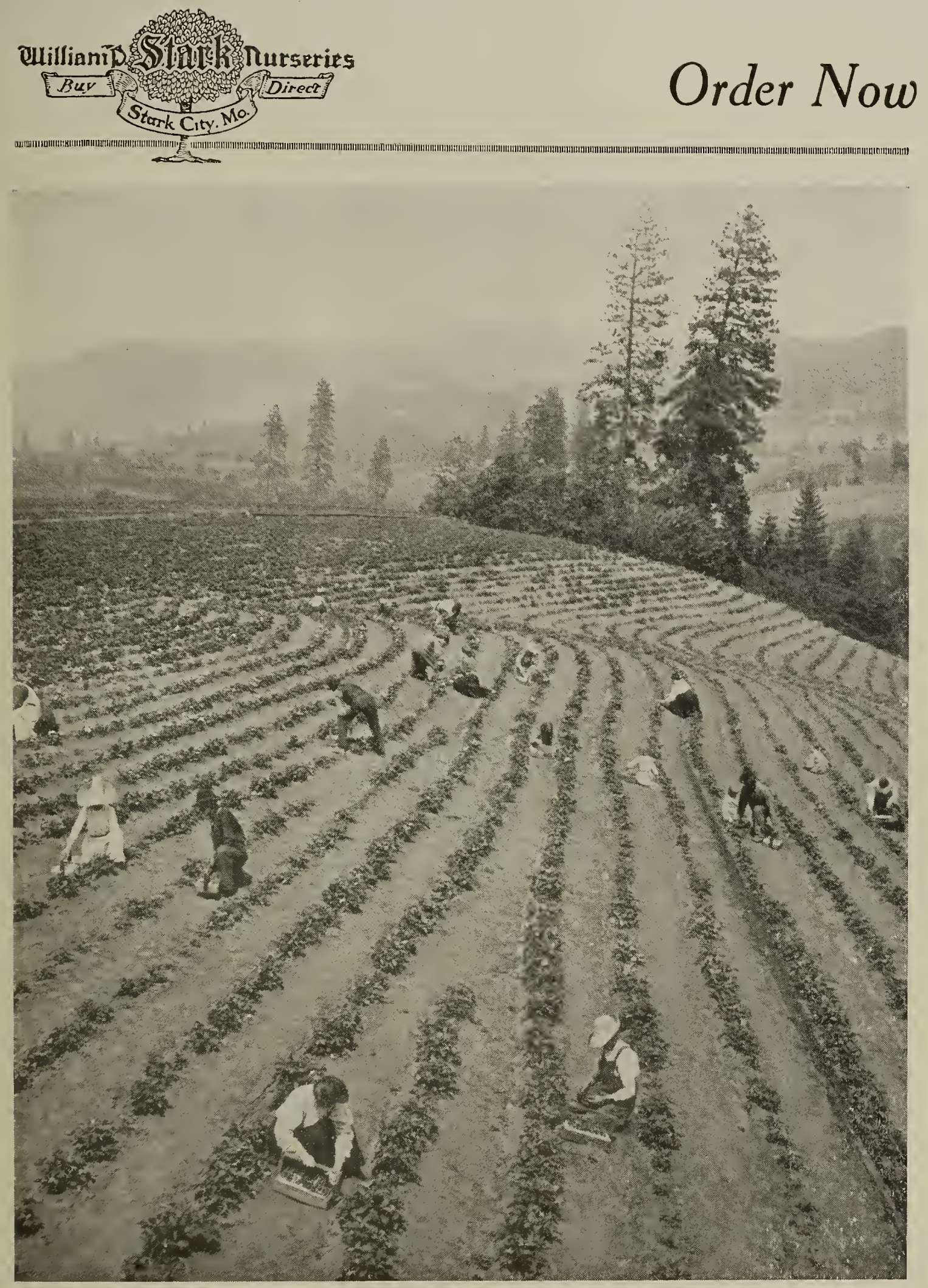

You Will Succeed with William P. Stark Plants.

Our Strawberry plants are grown in the heart of the famous Ozark Strawberry country. They are extra hardy, extra vigorous and prolific plant-makers and fruit-bearers. They are adapted to your section and you will be pleased with the splendid results they give. Because of their heavy, well-formed crowns and abundant roots, they succeed where weaker, less vigorous plants fail.

Send Us Your Order Now. Early-set plants make 20 to 40 new runner-plants. Early planting means bigger crops.

We dig and ship direct from the field when Government Weather Bureau Service reports conditions favorable to planting in your section. We handle and pack with such care that our plants deliver to all parts of the country in fresh condition. Safe arrival guaranteed. We want your order and assure you the best service the William P. Stark Nurieries can give. Your order will have personal attention, it will be packed carefully and it will be shipped at just the right time. Please use the order blank in writing us.

WILLIAM P. STARK NURSERIES, Stark City, Missouri. 


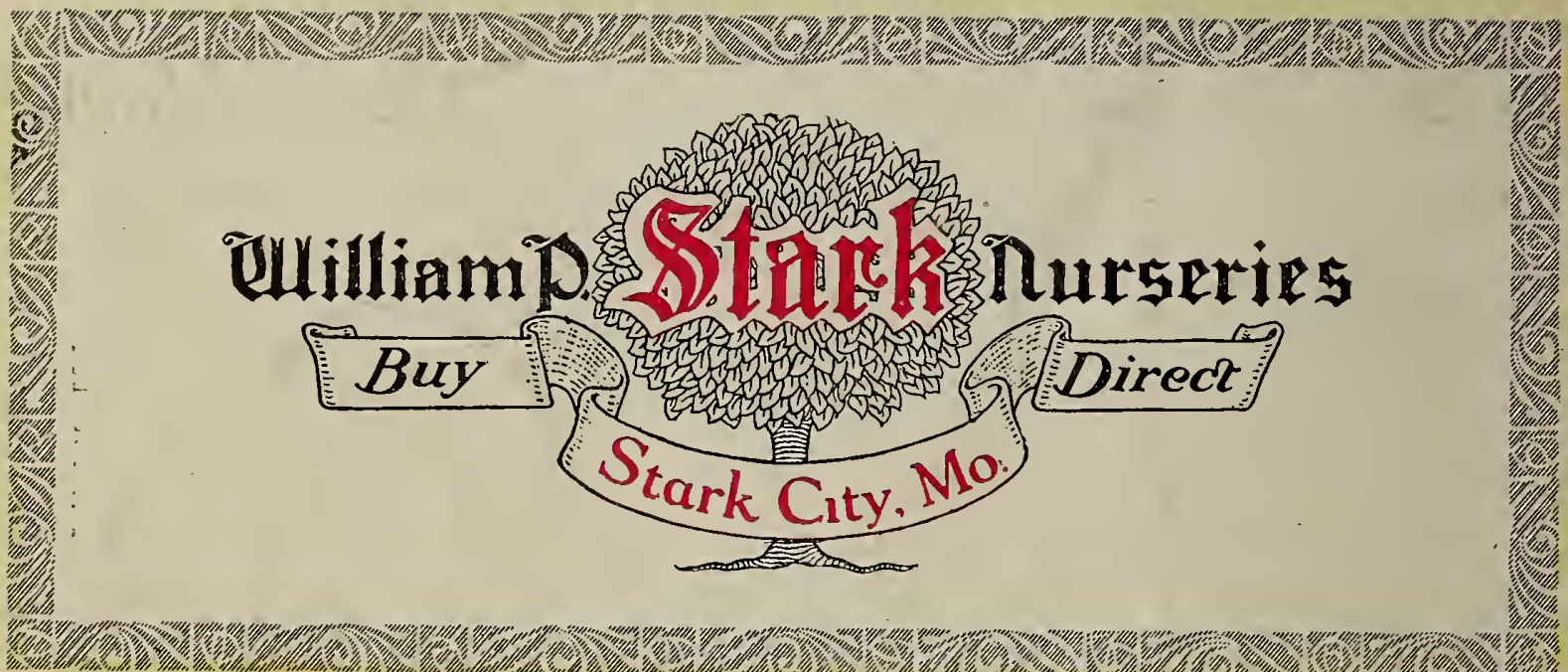

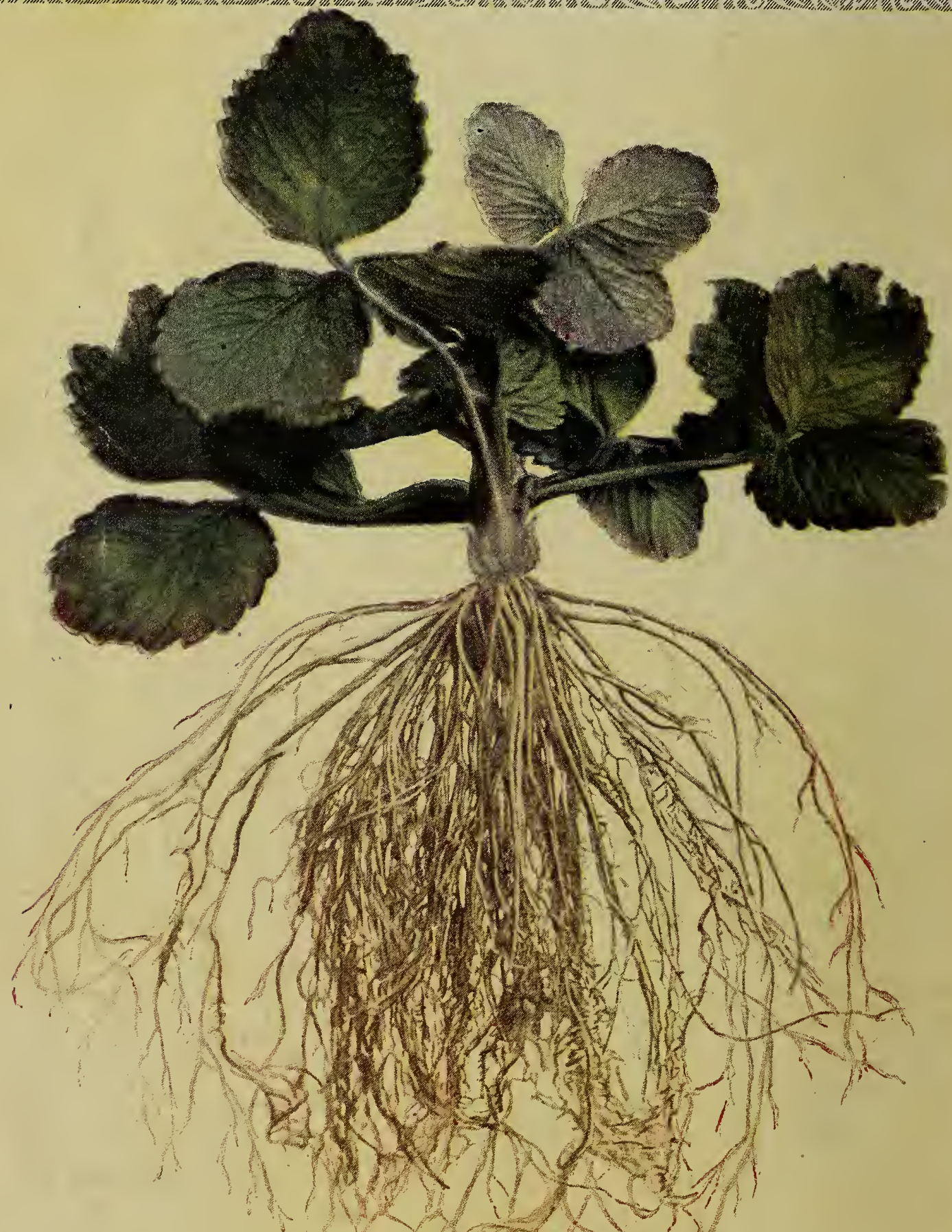

Stark Ozark Mountain Grown Strawberry Plants

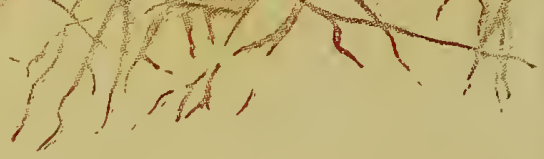

